\title{
Type IV pili is a critical virulence factor in clinical isolates of Paenibacillus thiaminolyticus
}

Christine Hehnly ${ }^{1}$, Aiqin Shi ${ }^{1}$, Paddy Ssentongo ${ }^{2}$, Lijun Zhang ${ }^{1}$, Albert Isaacs ${ }^{3}$, Sarah U.

Morton $^{4}$, Nicholas Streck ${ }^{5}$, Petra Erdmann-Gilmore ${ }^{6}$, Igor Tolstoy ${ }^{7}$, R. Reid Townsend ${ }^{6}$, David

D. Limbrick ${ }^{9}$, Joseph N. Paulson ${ }^{9}$, Jessica E. Ericson ${ }^{10}$, Michael Y. Galperin ${ }^{7}$, Steven J.

Schiff ${ }^{2,11}$, James R. Broach ${ }^{1,12}$

1. Institute for Personalized Medicine, Department of Biochemistry and Molecular Biology, The Pennsylvania State University College of Medicine, Hershey, PA

2. Center for Neural Engineering, Department of Engineering Science and Mechanics, The Pennsylvania State University, University Park, PA; Department of Public Health Sciences, The Pennsylvania State University College of Medicine, Hershey, PA

3. Division of Neurosurgery, Department of Clinical Neuroscience, University of Calgary, Calgary, Alberta, Canada

4. Division of Newborn Medicine, Boston Children's Hospital and Department of Pediatrics, Harvard Medical School, Boston, MA

5. Department of Pathology and Laboratory Medicine Division of Clinical Pathology, The Pennsylvania State University College of Medicine, Hershey, PA

6. Department of Medicine, Washington University School of Medicine, St. Louis, MO, USA

7. National Center for Biotechnology Information, National Library of Medicine, National Institutes of Health, Bethesda, MD

8. Department of Neurological Surgery, Washington University School of Medicine, St. Louis, MO, USA

9. Department of Biostatistics, Product Development, Genentech Inc., San Francisco, CA

10. Division of Pediatric Infectious Disease, The Pennsylvania State University College of Medicine, Hershey, PA

11. Department of Neurosurgery, The Pennsylvania State University College of Medicine, Hershey, PA; Center for Infectious Disease Dynamics, and Department of Physics, The Pennsylvania State University, University Park, PA

12. Corresponding Author:

jbroach@pennstatehealth.psu.edu 717-531-8586

Tables: 4

Figures: 5

Supplement: 5 Figures, 4 Tables 


\section{Abstract}

Hydrocephalus, the leading indication for childhood neurosurgery worldwide, is particularly prevalent in low-and-middle-income countries (LMICs). Hydrocephalus preceded by an infection, or postinfectious hydrocephalus (PIH), accounts for up to $60 \%$ of hydrocephalus in LMICs. Since many children with hydrocephalus suffer poor long-term outcomes despite surgical intervention, prevention of hydrocephalus remains paramount. Our previous studies implicated a novel bacterial pathogen, Paenibacillus thiaminolyticus, as a contributor to PIH in Uganda. Here we report the isolation of three P. thiaminolyticus strains, Mbale, Mbale2, and Mbale3, from patients with PIH and the demonstration that the three clinical isolates exhibit virulence in mice while $P$. thiaminolyticus type strain, B-4156, does not. We constructed complete genome assemblies of the clinical isolates as well as the reference strain and performed comparative genomics and proteomics analyses to identify potential virulence factors. One candidate virulence factor is a cluster of genes carried on a mobile genetic element that encodes a type IV pilus and is present in all three PIH patient strains but absent in the type strain. Proteomic and transcriptomic data confirmed the expression of this cluster of genes in the Mbale strain, while CRISPR-mediated deletion of the gene cluster substantially reduced the virulence of this strain. Our comparative proteogenomic analysis also identified various antibiotic resistance loci in the virulent strains. These results provide insight into the mechanism of virulence of Paenibacillus thiaminolyticus and suggest avenues for the diagnosis and treatment of this novel bacterial pathogen. 


\section{Author Summary}

Postinfectious hydrocephalus (PIH), a devastating sequela of neonatal infection, is associated with increased childhood mortality and morbidity. Paenibacillus thiaminolyticus was recently identified as the dominant organism highly associated with PIH in an African cohort. Our wholegenome sequencing, RNA sequencing and proteomics of three clinical isolates and a type strain in combination with CRISPR editing has revealed the type IV pili (T4P), encoded in a mobile genetic element, as a critical virulence factor for $P$. thiaminolyticus infection. Given the widespread presence of T4P in pathogens, the presence of T4P operon could serve as an important diagnostic and therapeutic target in P. thiaminolyticus and related bacteria. 


\section{Introduction}

Hydrocephalus is one of the most common brain disorders in children globally $[1,2]$ and the most common indication for pediatric neurosurgery [2]. A serious infection such as neonatal sepsis often precedes hydrocephalus [3], and postinfectious hydrocephalus (PIH) accounts for up to $60 \%$ of the nearly 400,000 children who develop hydrocephalus each year, principally in lowand middle-income countries (LMICs) $[1,3,4]$. PIH remains the leading cause of neurological morbidity and mortality worldwide despite recent clinical efforts to optimize the treatment $[5,6]$.

Strategies to prevent PIH have been thwarted for two principal reasons. First, standard clinical evaluation often fails to identify the pathogen(s) responsible for the underlying infectious episodes that precede $\mathrm{PIH}$ [7], precluding optimized or targeted treatment of the underlying infections. Second, the underlying pathophysiologic changes that lead to hydrocephalus following infection remain unknown [8]. Unfortunately, even children who undergo surgical treatment for hydrocephalus early in life can suffer very poor long-term outcomes $[6,9]$. Therefore, major advances in the health of these children will require preventing infection by targeting both the underlying pathogens and their routes of infection [10-12], as well as improving treating infections with more optimal antibiotics and adjunctive therapies that can reduce the likelihood of subsequently developing hydrocephalus.

We have identified and isolated a novel pathogenic bacterial strain, Paenibacillus

thiaminolyticus Mbale, as a likely causative agent in a significant fraction of a cohort of PIH cases in Uganda [13]. We showed that P. thiaminolyticus Mbale is lethal to mice following 
peritoneal injection, whereas injection of the $P$. thiaminolyticus type strain, NRRL ${ }^{\mathrm{T}} \mathrm{B}-4156$ (B4156), does not cause lethality. Paenibacillus species have been isolated and studied from various sources, particularly in agricultural and industrial applications [14]. Although some species such as $P$. alvei and $P$. larvae are known to cause widespread disease in honeybees [15], until recently only anecdotal cases of human disease associated with Paenibacillus have been reported [16-21]. We recently confirmed our initial report implicating $P$. thiaminolyticus as a causative agent of PIH by identifying P. thiaminolyticus infection in the CSF of $41 \%$ of 205 infants with PIH. Moreover, we detected P. thiaminolyticus in CSF samples from a significant fraction of neonates with clinical sepsis (Morton et al., unpublished data). Finally, we have isolated two additional clinical $P$. thiaminolyticus strains from patients in the larger PIH cohort and whose properties are described in this report.

Pathogenic bacteria typically have specific proteins, or virulence factors (VFs), that aid in their ability to survive and propagate in their hosts. Given the differential virulence between the B4156 strain and our clinical isolates, we hypothesized that clinical isolates from our patients carry VFs that are absent in the nonpathogenic B-4156 strain. To address this hypothesis, we used genomic analysis to compare the predicted proteome of several clinical isolates to the B4156 type strain and confirmed gene expression with RNA sequencing and proteomic analysis (Fig S1). For functional confirmation, we developed a novel CRISPR-Cas9 gene deletion system and applied it to one of the clinical isolates to confirm that a type IV pilus (T4P) identified with comparative proteogenomics is a critical VF. These results provide insight into the mechanism of virulence of $P$. thiaminolyticus and suggest avenues for diagnosis and treatment of this novel bacterial pathogen. 


\section{Materials and Methods}

The Paenibacillus thiaminolyticus type strain NRRL B- $4156^{\mathrm{T}}$ was obtained from the United States Department of Agriculture Agricultural Research Service Culture Collection (NRRL, Peoria, IL).

\section{Clinical Microbiology}

Isolation and genome assembly of the Mbale strain were previously described [13]. To recover additional clinical isolates, $1 \mathrm{ml}$ aliquots of CSF from sixty-three PIH patients [13] were inoculated into BD BACTEC ${ }^{\mathrm{TM}}$ Lytic Anaerobic Medium culture bottles supplemented with 1 $\mathrm{ml}$ of defibrinated horse blood (Thermo Scientific). Culture bottles were incubated in a BD BACTEC $^{\mathrm{TM}}$ FX instrument and monitored for bacterial growth for up to 14 days. Culture bottles that were positive for bacterial growth were subcultured in $\mathrm{BD} \mathrm{BBL}^{\mathrm{TM}}$ Chocolate II and CDC Anaerobe 5\% Sheep Blood agar plates and incubated at $37^{\circ} \mathrm{C}$ under anaerobic conditions (Anoxomat, Advanced Instruments). Culture bottles that remained negative after 14 days were also subcultured under anaerobic conditions and did not result in bacterial growth. All subsequent culturing after initial anaerobic conditions were done aerobically. Two CSF samples were positive for growth in culture bottles. As previously described, colonies from subculture plates were used for Gram stain, organism identification by MALDI-TOF, biochemical testing, and antimicrobial susceptibility testing [13]. Biochemical testing was performed using API 50 $\mathrm{CH}$ strip following manufacturers protocol. Susceptibility testing and interpretations were performed by E-test method using Clinical and Laboratory Standards Institute (CLSI) guidelines. 


\section{Bacterial genome sequence and assembly}

Bacterial cultures were inoculated in either Luria-Bertani (LB) broth from mono-isolates or anaerobic culture bottles. DNA was extracted using either the Prep Cell Culture DNA Isolation protocol (Bionano Genomics, San Diego, CA) or Zymobiomics DNA kit following the manufacturer's protocol. DNA samples were then sheared to about $400 \mathrm{bp}$ fragments using the E220 Focused ultrasonicator (Covaris, Woburn, MA), and libraries were prepared with Hyper prep kit (Kapa Biosystems, Wilmington, MA) following the manufacturer's protocol and sequenced on a MiSeq v3 600 cycle at 10 pM and 15\% phiX with 10 million reads per sample. For long-read sequencing, libraries were prepared with $1.5 \mu \mathrm{g}$ DNA following the Native barcoding genomic DNA (with Exp-NBD104, EXP-NBD-114, and SQK-LSK109) with minor modifications using Kapa or NEB T4 ligase and end-repair enzymes without the use of the FFPE DNA Repair Mix.

Genomes of strains Mbale and NRRL B-4156 were assembled as previously described [22]. The genomes of two additional clinical isolates, Mbale2 and Mbale3, were assembled using the same protocol. Briefly, long reads generated on a MinIon (Oxford Nanopore) were preprocessed using Albacore, assembled with Canu [23] and corrected with Pilon [24].

\section{Genome annotation and protein comparison}

We used the Prokaryotic Genome Annotation Pipeline (PGAP) [25, 26] through RefSeq and RASTtk annotation summarized by the PATRIC database to annotate the three clinical isolates and B-4156 strains. Genome annotation and a functional-based comparison were performed using RASTtk [27] with the default parameters for the P. thiaminolyticus Mbale and B-4156 
strains. Furthermore, the PATRIC database [28] was used for protein comparisons of the annotations (70\% minimal coverage and 30\% minimal identity) and the proteomics (50\% minimal coverage and 30\% minimal identity). Mapping of proteins to the genomic assembly was done using CGView [29]. OrthoVenn2 [30] with default settings was used to compare the predicted proteins with proteins from previously sequenced related bacteria, and Gene Ontology terms for the mapped genes were plotted with ggplot2 [31] in R Statistical Computing Program version 4.0.4. An average nucleotide identity calculator was used to compare the overall nucleotide identity [32]. PilFind using default settings was used to identify the motifs in hypothetical proteins for a transmembrane domain [33]. PHASTER was used to identify specific phage insertions in each genome [34].

\section{RNA isolation, sequencing and analysis}

Bacteria were grown in M9 mineral medium with $0.4 \%$ glucose or LB media and samples were prepared at five stages of growth from both cultures to evaluate the span of gene expression. RNA was isolated using the Direct-zol RNA Miniprep kit (Zymo, USA) following the manufacturer's bead beating and DNase I treatment protocol. RNA was prepared for sequencing with the NEBNext rRNA depletion kit (E7850, New England Biolabs, USA), followed by the Stranded Total RNA Prep (Illumina, USA) following the manufacturer's protocol. Counts were generated with HTSeq aligned to the respective PGAP annotated genome. Comparisons were done with the Mbale and NRRL B-4156 aligned to the Mbale annotation. Statistical analysis was done with DESeq2 [35] in R.

\section{Proteomic preparations and analysis of isolates}


Three liquid cultures from three separate colonies each of strains Mbale and B-4156 were analyzed concurrently. All samples were digested with trypsin after protein denaturation, reduction, and alkylation essentially as described previously [36, 37]. The labeled peptides were analyzed by nano-scale liquid chromatography coupled with tandem mass spectrometry (nanoLC-MS/MS). The samples were resuspended in solution A (1\% formic acid) and $2.5 \mu 1$ loaded onto a $75 \mu \mathrm{m}$ i.d. $\times 50 \mathrm{~cm}$ Acclaim ${ }^{\circledR}$ PepMap 100 C18 RSLC column (Thermo-Fisher Scientific) on an EASY nanoLC (Thermo Fisher Scientific) at a constant pressure of 700 bar in solution A. Prior to sample loading the column was equilibrated to solution A for a total of $11 \mu \mathrm{l}$ at 700 bar pressure. Peptide chromatography was initiated with mobile phase solution A containing 2\% solution B (100\% acetonitrile, $1 \%$ formic acid) for $5 \mathrm{~min}$, then increased to $20 \%$ solution B over $100 \mathrm{~min}$, to $32 \%$ solution B over $20 \mathrm{~min}$, to $95 \%$ solution B over $1 \mathrm{~min}$ and held at $95 \%$ solution B for $29 \mathrm{~min}$, with a flow rate of $300 \mathrm{nl} / \mathrm{min}$. Data was acquired in data-dependent acquisition (DDA) mode. The full-scan mass spectra were acquired with the Orbitrap mass analyzer with a scan range of $\mathrm{m} / \mathrm{z}=325$ to 1500 and a mass resolving power set to 70,000 . Ten data-dependent high-energy collisional dissociations were performed with a mass resolving power set to 17,500 , a fixed lower value of $\mathrm{m} / \mathrm{z} 100$, an isolation width of $2 \mathrm{Da}$, and a normalized collision energy setting of 27. The maximum injection time was $60 \mathrm{~ms}$ for parent-ion analysis and product-ion analysis. The target ions that were selected for MS/MS were dynamically excluded for 20 sec. The automatic gain control (AGC) was set at a target value of $10^{6}$ ions for full MS scans and $10^{5}$ ions for MS2. Peptide ions with charge states of one or $>8$ were excluded from MS/MS interrogation. 
Data from the mass spectrometer were converted to peak lists and the MS2 spectra were analyzed using Peaks software [38]. The software was used to search a database of each strain's PGAP annotations with trypsin specificity. A maximum of 3 missed cleavages was allowed. The searches were performed with a fragment ion mass tolerance of $50 \mathrm{ppm}$ and a parent ion tolerance of $25 \mathrm{ppm}$. Carbamidomethylation of cysteine was specified in Peaks as a fixed modification. Deamidation of asparagine, formation of pyro-glutamic acid from N-terminal glutamine, acetylation of protein N-terminus, oxidation of methionine, and pyrocarbamidomethylation of N-terminal cysteine were specified as variable modifications. Peptide and protein identifications were exported and results were filtered post processing using peptide $10 \log \mathrm{P}$ values.

\section{Genome editing with CRISPR-Cas9}

All plasmids for genome editing were constructed in E. coli DH5a (fhuA2 lac(del)U169 phoA glnV44 $\Phi 80^{\prime}$ lacZ(del)M15 gyrA96 recAl relAl endA1 thi-1 hsdR17) and, after sequencing confirmation, were transformed into E. coli BW29427 (RP4-2(TetS, kan1360::FRT) thrB1004 AlacZ58(M15) $\Delta d a p A 1341: \because\left[\mathrm{erm} \mathrm{pir}^{+}\right] \mathrm{rpsL}(\mathrm{strR}$, thi- hsdS- pro-) (The Coli Genetic Stock Center) selecting on LB medium containing $50 \mu \mathrm{g} / \mathrm{ml}$ chloramphenicol and $100 \mathrm{ug} / \mathrm{ml}$ diaminopimelic acid (DAP). All plasmid constructions were performed with the appropriate enzymes from New England Biolabs. Our genome editing vector was derived from plasmid pJOE9734 (Bacillus Genetic Stock Center) [39], which contains the oriT/traJ origin of transfer, $k a n R$ antibiotic resistance gene and cas 9 under control of the mannose promoter (PmanPA) from Bacillus subtilis 168 [40]. Furthermore, it carries the pE194ts origin of replication, making its 
propagation temperature sensitive. A chloramphenicol resistance gene (cat) and its promoter from pAD43-25 were cloned into pJOE9734 at the AfeI site to create plasmid pAS1.

For genome editing to delete the type IV pilus operon, about 400bp DNA upstream and downstream of the T4P operon were amplified separately and ligated by overlap PCR to produce the template sequence for gene deletion by homologous recombination. This DNA product was cloned into pAS1 at $S f i$ s site to generate plasmid pAS2. A guide RNA targeted to Type IV pilus operon was designed with the Integrated DNA Technologies (Coralville, IA) online guide RNAs design tool (https://www.idtdna.com/site/order/designtool/index/CRISPR PREDESIGN) and cloned into pAS2 at BsaI site to produce pAS3. Plasmid pAS3 was transformed into E. coli BW29427 and a transformant mated with $P$. thiaminolyticus Mbale at $30^{\circ} \mathrm{C}$ on LB minus DAP overnight and then resuspended in $1 \mathrm{ml} \mathrm{LB}$. Varying volumes were plated on LB plates with 25 $\mu \mathrm{g} / \mathrm{ml}$ chloramphenicol at $30^{\circ} \mathrm{C}$ for two days and single colonies were picked for confirmation of successful conjugation by PCR. For cas9 induction, the pAS3-positive colonies were cultured in $10 \mathrm{ml} \mathrm{LB}$ with $5 \%$ mannose and chloramphenicol at $30^{\circ} \mathrm{C}$ at $50 \mathrm{rpm}$ for two days, then spread on LB plus chloramphenicol plate and cultured in $39^{\circ} \mathrm{C}$ incubators overnight to induce loss of pAS3. Resultant colonies were confirmed for deletion of the T4P operon by PCR. Primers used are summarized in Table S1.

\section{Virulence testing using C57BL/6J mice}

All animal experiments were performed with oversight by the Penn State Institutional Animal Care and Use Committee, and with Institutional Biosafety Committee approval at biosafety level 2 (BSL2). The virulence of Mbale and $\Delta($ pilT pilC pilB) $(\mathrm{KO})$ strains was tested using the mouse 
infection model as previously described [13]. Briefly, cultures were grown in liquid LB overnight at $37^{\circ} \mathrm{C}$ and then subcultured onto blood agar plates overnight. Bacteria were harvested from plates and resuspended in saline to a concentration of $2 \times 10^{9}$ cells $/ \mathrm{ml}$. C57BL $/ 6 \mathrm{~J}$ mice were inoculated with $100 \mu \mathrm{l}$ of bacterial suspension intraperitoneally and followed for 30 days or until death.

\section{PCR of pilT gene}

DNA was isolated as above from either cerebrospinal fluid (CSF) or blood from patients with hydrocephalus. PCR of the pilT gene was performed with OneTaq (NEB, M0207) with $500 \mathrm{nM}$ of forward (gatcataatcaatgagcceggtcatgg) and reverse (cttgtgcgaaggcgetgcga) primers in $25 \mu 1$ reactions. Amplified products were separated on a 1\% agarose gel and visualized after staining with ethidium bromide, scoring for the presence of a $200 \mathrm{bp}$ product from pilT. 


\section{Results}

\section{Complete assemblies of clinical isolates and type strain B-4156}

We previously described the isolation of a novel bacterial strain, which we designated

Paenibacillus thiaminolyticus Mbale, from the cerebral spinal fluid (CSF) of a patient with post infectious hydrocephalus (PIH) [13] and identified it as P. thiaminolyticus based on MALDITOF analysis, rRNA similarity, average nucleotide identity and phylogenetic analysis [22]. Two additional isolates, which we designated Mbale2 and Mbale3, were recovered from the CSF of two additional patients with PIH and also identified as $P$. thiaminolyticus by MALDI-TOF analysis. Computerized tomography scans of the brains of the infants from which these strains were recovered are shown in Fig 1A. We previously provided the complete genome assemblies of the Mbale strain and the P. thiaminolyticus type strain NRRL B-4156 ${ }^{\mathrm{T}}$ (B-4156) [22]. The B4156 strain assembly yielded a complete 6,613-kilobasepair (kbp) chromosome from long-read sequencing, while the initial clinical Mbale strain required optical mapping to construct one complete chromosome from three contigs assembled by the long-read sequencing; three shorter contigs remained unmapped (Fig 1B, Table 1). PHASTER analysis identified 2 of the 3 unmapped contigs as either complete or incomplete phage sequences (Fig S2B) [34]. The third unmapped contig likely constitutes an insertion in the chromosome identified by optical genome mapping but flanked by extended repeated sequences, rendering it unmappable by short and long read sequencing. The complete sequence of the two new isolates revealed a single $6,460 \mathrm{kbp}$ contig for the Mbale2 strain and two contigs, 6,561 kbp and $12 \mathrm{kbp}$, for the Mbale3 strain (Table 1, Fig 1B). PHASTER analysis identified the $12 \mathrm{kbp}$ contig of Mbale3 as an incomplete phage genome (Fig S2, Table 1). We further confirmed the species assignment with average nucleotide 
identity (ANI) [32]. The average two-way ANI of the Mbale, Mbale2, and Mbale3 to B-4156 were $97.05 \%, 97.03 \%$, and $97.01 \%$, respectively, which fall above 95\% sequence similarity across species [41]. Biochemical testing using API test strips read at 48 hours also identified B4156, Mbale, Mbale2, and Mbale3 as P. thiaminolyticus at 99.9\%, 99.9\%, 97-98.6\%, and 91.698.9\% confidence (Table $\mathbf{S 2}$ ).

\section{Genomic comparisons of $\boldsymbol{P}$. thiaminolyticus B-4156 and clinical isolates}

We performed a Progressive Mauve alignment [42] to identify the genomic differences between the clinical isolates and type strain B-4156. The multiple sequence alignment identified 12 locally colinear blocks (LCB) between the four strains, representing sequences with conserved segments and no rearrangements (Fig 1C). The genomes also contained several regions of low sequence similarity. The contigs that did not assemble into the chromosome had no homology to B-4156. The chromosome of the Mbale strain is approximately $132 \mathrm{~kb}$ larger than that of B4156, whereas Mbale2 and Mbale3 genomes are about $153 \mathrm{kbp}$ and $40 \mathrm{kbp}$ smaller than the genome of B-4156 strain, respectively.

Horizontal transfer of mobile genetic elements (MGEs) facilitates rapid evolution of microbial genomes $[43,44]$. To investigate genomic differences driven by MGEs, we used Mobile Genetic Element Finder (MGEFinder) [45] and PHASTER [34]. We identified 320 unique sequences and 186 clusters that are identified using CD-HIT-EST at $90 \%$ sequence identity over $85 \%$ of their sequence per the MGEFinder methods. The 320 unique sequence insertions range from 70$82,113 \mathrm{bp}$ in length in the clinical isolates (median, $168 \mathrm{bp}$; interquartile range [IQR], 112-352 
bp). Mbale, Mbale2, and Mbale3 carry 158, 156, and 129 inserted sequences, respectively, as well as 11, 4, and 5 phage insertions (Fig 1D).

To assess the possible functional significance of the insertion sequences predicted from the MGEFinder, we assessed their coding potential by string analysis and RAST annotations. This analysis yielded 676 predicted coding sequences associated with 22 Gene Ontology terms (Fig S3), dominated by genes associated with DNA processing and the establishment of competence to acquire insertion sequences. All three isolates also contained separate insertions carrying genes encoding vancomycin B-type resistance protein VanW, spore coat protein CotI, and the transcription regulator of AraC family (Fig 1D). Antibiotic resistance testing confirmed that the isolates were resistant to vancomycin (Table S3). In addition, strains Mbale and Mbale2 carried a common $12 \mathrm{kbp}$ insert spanning a type IV pilus (T4P) operon linked to a beta-lactamase class C-like penicillin binding protein gene. Although not predicted to be an insertion by MGEFinder, Mbale 3 also carries a $14 \mathrm{kbp}$ insertion containing the T4P genes identified by annotation linked to a beta-lactamase class C-like penicillin binding protein gene (Fig 1D). Consistent with the presence of a beta-lactamase gene in the isolates, two of the three isolates were resistant to the beta-lactam antibiotics ampicillin and penicillin.

\section{Predicted proteomes of the clinical isolates and the type strain}

The number and classes of proteins predicted to be encoded by each of the three clinical isolates and the type strain, as determined by RefSeq or PATRIC, are listed in Table 1. Consistent with the high similarity of the genomes of clinical isolates and B-4156, these genomes carry very similar sets of metabolic genes and, accordingly, are predicted to encode similar metabolic 
pathways. These include, among others, similar systems of amino acid biosynthesis, purine, pyrimidine, and cofactor biosynthesis, carbohydrate and lipid metabolism, amino acid and protein degradation, respiration, and energy metabolism (Table 2). Many of the predicted carbohydrate metabolic pathways were confirmed by biochemical metabolism testing (Table S2). The clinical isolates and B-4156 all carry a number of antibiotic resistance genes and contain a thiol activated cytolysin, a potential virulence factor. B-4156 carries an operon encoding the type VII secretion, which the clinical isolates lack.

As a means of identifying potentially clinically relevant features of the pathogenic strains, we used OrthoVenn2 to compare the predicted proteome across the clinical isolates and B-4156, which identified 6608 unique coding regions across all four strains with 5109 coding regions present in all isolates (Fig 2A). Overall, the clinical strains share more coding regions among themselves than with the type strain (Fig 2B). Specifically, the three clinical isolates share 342 coding regions that are absent from B-4156. Gene ontology of these 342 coding regions returned 39 terms with the largest number of genes associated with "sequence-specific DNA binding", "plasma membrane", and "sporulation resulting in the formation of a cellular spore" (Table S4). Several genes populate terms such as secretion, iron, and response to toxins that could contribute to the difference in virulence between the isolates and the reference strain (Fig 2C). In addition to these strict paralogous coding regions, each of the three clinical isolates carry a number of unique coding regions, eight of which encode functionally identical or related proteins. These eight regions, versions of which are present in all three clinical isolates but not B-4156, include three genes that encode the T4P, including the twitching motility protein (pilT), type IV fimbrial assembly protein (pilC), and leader prepilin peptidase (pilD) (Table 3). Mbale2 and Mbale3 
carry an additional N-methyltransferase related to the T4P. In addition, the clinical isolates carry three phosphorous metabolism enzymes provisionally assigned to the phosphoenolpyruvate phosphomutase subsystem that are responsible for the first step of the carbon-nitrogen bond formation for the synthesis of a broad class of antibiotics (Table 3). The strains also carry single predicted proteins involved in tryptophan and teichoic acid processing. These unique predicted proteins listed in Table 3 were all confirmed in the Mbale strain by proteomic analysis (see below). In sum, our genomic annotation reveals several candidate genes potentially important for pathogenesis, including antibiotic resistance genes and the T4P system.

\section{RNA and Protein Expression Analysis of Mbale and the Type Strains}

As an initial step in assessing whether the predicted coding regions are functional, we performed sequence analysis of RNA isolated from Mbale and B-4156 grown in two different media, LB and minimal salts (M9) plus glucose, at five stages of growth (lag phase, middle log phase, late $\log$ phase, stationary phase and death phase) (Fig 3A). We identified 6285 and 5817 unique transcripts from the Mbale and B-4156 strains, respectively, with 5893 transcripts present in both strains, 400 unique to Mbale and 8 unique to B-4156 (Fig 3C). Unsupervised hierarchical clustering of the most variable expressed transcripts provided clear discrimination based on strain and stage of growth, with some distinction related to growth media (Fig $\mathbf{3 A})$.

To further assess the functionality of predicted proteins, we performed proteomics analysis of the B-4156 and Mbale strains growing exponentially in LB medium. The de novo analysis identified 193,878 and 194,234 peptides in the Mbale and B-4156 strains, respectively, which mapped to 2,488 and 2,531 proteins based on PGAP annotation. Two thousand forty-six were present in 
both strains while 450 unique proteins were expressed in Mbale and 468 in B-4156 (Fig 3D).

String analysis of the unique proteins in each strain confirmed the presence of proteins from similar metabolic pathways despite the unique protein sequences. Two unique terms, "Bacterial secretion system" and "Protein export" were identified in the Mbale strain (Fig 3B). The proteins assigned to these terms encode for the SecA secretion pathway $(\sec Y, \sec A, f f H, \operatorname{lasp} A$, $\sec F$, $s e c D)$. In addition, the pilC- and tagG-encoded predicted proteins unique to Mbale were confirmed.

\section{All three clinical isolates carry a complete T4P operon.}

The initial annotation of the 12-14 kbp insertion encoding T4P components documented a common gene organization for the element in all three clinical isolates, which encompasses four genes encoding proteins associated with the T4P assembly: pilD, pilB, pilC and pilT. This annotation, though, failed to identify genes essential for a complete T4P assembly, namely, those encoding the minor and major pilins and the alignment proteins, PilM, PilO and PilN [46]. However, using BLAST and alignment with COGs [47] and Pfam [48] in comparison to the type II secretion system databases [49-51], we identified a number of these essential assembly genes in the cluster (Fig 4A, Table 4). Furthermore, we used pilFind to identify three genes that encode for the transmembrane domain on the $\mathrm{N}$-terminus characteristic of pilins (Table 4), one of which had homology to the pseudopilin protein GspH. Comparison of the gene order in the 14 kbp insertion of $P$. thiaminolyticus Mbale with the previously characterized pil operons from other Gram-positive bacteria $[33,52]$ showed the closest match to the pil operons of Clostridium cellulolyticum H10 and Bacillus sp. NRRL B-14911 (Fig. S4). The Mbale2 and Mbale3 insertion sequences contained the same gene order present in the Mbale strain (Fig. 3A). In contrast, strain 
B-4156 encodes only a truncated pilB gene (encoding the first 60 amino acids of PilB) and lacks the remaining genes required for complete assembly of the T4P. As shown in Fig 4C, all of these genes in T4P cluster are transcribed in the Mbale strain as is the pilB fragment in B-4156.

The above analysis indicates that the clinical isolates possess the components necessary for assembly of a T4P and that, at least in the Mbale strain, those genes are transcribed as well as translated. This genetic feature of the clinical isolates may account for our anecdotal observation that cells of strain Mbale appear to have higher virulence after growth on agar plates than after growth in liquid culture (data not shown). While we have not rigorously quantified this observation, it is consistent with the reported higher T4P production in the surface-grown Clostridium perfringens [53]. In both $C$. perfringens and strain Mbale, the T4P assembly ATPase, PilB, contains an N-terminal c-di-GMP-binding MshEN domain [54] that has been implicated in the regulation of various cellular processes in pathogenesis (Fig. 4B).

\section{The Mbale T4P system is a virulence factor}

To directly test the role of the T4P in virulence, we used CRISPR-Cas9 to construct a variant of the Mbale strain from which the pilB, pilC, and pilT genes were deleted. As described in Materials and Methods, we constructed plasmid pAS3 in which a mannose-inducible promoter controlled Cas9 expression, a sgRNA targeted the region adjacent to the pilC gene (Fig 5B) and homology-directed recombination template that would yield a deletion of the three targeted genes (Fig S5). Following the introduction and propagation of the plasmid in Mbale, we recovered several colonies from which the three genes were deleted. We assessed the virulence of one of the mutant strains in a mouse infection model (Fig 5A) and determined that, with 
identical bacterial doses, none of the Mbale injected mice survived while all of the mice injected with the deletion strain survived (Fig 5B, p<0.0001). This result confirms that the T4P system in the Mbale strain contributes to its pathogenesis.

\section{pilT may serve as a diagnostic marker for $P$. thiaminolyticus infections.}

We previously identified $P$. thiaminolyticus in the CSF of a subset of patients with PIH or neonatal sepsis (Morton et al, unpublished). To determine whether the T4P is associated with infection, we used PCR to probe for the pilT gene, which as noted above is present in all clinical isolates but absent in the reference strain, in clinical samples previously determined to be positive or negative for Paenibacillus. As a control, we probed for the pilT gene in all three clinical isolates and B-4156 and showed that we could detect it in the clinical strains but not in the type strain (Fig 5D). Previously, we defined Paenibacillus infections in patients using qPCR to the thiaminase gene (Morton et al., unpublished). Examining clinical samples, we detected pilT in the CSF of all three PIH cases with positive $P$. thiaminolyticus cultures and both neonates with sepsis who subsequently developed PIH with $P$. thiaminolyticus infections. We did not detect pilT in CSF samples previously determined to be Paenibacillus negative (Fig 5D). These results suggest that the presence of pilT correlates with infection by Paenibacillus, consistent with a role for the T4P cluster in pathogenesis. Moreover, they suggest that Paenibacillus may be detectable in clinical samples prior to the onset of hydrocephalus. 


\section{Discussion}

Paenibacillus species have been isolated and studied from various sources, particularly in agricultural and industrial settings. The rod-shaped, Gram-positive, endospore-forming aerobic bacteria were initially assigned to the genus Bacillus but were subsequently recognized as substantially distinct from other Bacillus spp. and assigned to a separate genus Paenibacillus (“almost bacillus") with Paenibacillus polymyxa as the type species [55]. Since then, this genus has significantly expanded through assignment of many newly described species and transfer of several other former Bacillus species, such as Bacillus alginolyticus, Bacillus glucanolyticus, and Bacillus thiaminolyticus [56]. This genus, along with several others, such as Brevibacillus and Cohnella, was subsequently assigned to the new family Paenibacillaceae within the order Bacillales [57], further separating it from Bacillus proper.

We recently identified $P$. thiaminolyticus as a novel pathogen associated with postinfectious hydrocephalus (PIH) and neonatal sepsis (NS) in Ugandan infants. Even though Paenibacillus species are highly prevalent in the environment, they had not previously been implicated as a significant human pathogen. Accordingly, we know very little about the mode of pathogenesis of the bacteria or the virulence factors responsible for the severe disease observed in children. However, understanding the virulence of the clinical isolates of $P$. thiaminolyticus provides insight into identification, diagnosis and treatment of infection, information essential for preventing devastating sequelae such as $\mathrm{PIH}$.

Our sequencing, assembly and functional annotation of the genomes of three clinical isolates and the type strain of $P$. thiaminolyticus has provided a comprehensive catalog of the genetic content 
of these strains and our transcriptomic and proteomic analysis confirmed expression of a significant fraction of the predicted genes (Table 2, Fig 3). While the clinical isolates exhibit more than 97\% identity with the type strain (Fig 1B), they differ from the type strain predominantly by the presence of a large number of insertions, likely derived by horizontal transfer of mobile genetic elements (MGEs) (Fig 1C). These insertions are predicted to encode mobile element proteins, hypothetical proteins, multiple AraC family transcriptional regulators, phage proteins and spore coat protein, CotI. The AraC family of transcriptional regulators have been implicated in regulation of proteins of diverse function including virulence factors [58, 59]. All three isolates carry an insertion with the vancomycin B-type resistance gene, van $W$, and all three isolates are non-susceptible to vancomycin in culture (Fig 1C, Table S3). Moreover, all three strains carry a beta-lactamase gene and two of the three isolates exhibit resistance in culture to the beta-lactam antibiotic penicillin and ampicillin. Since the first-line antibiotic regimen recommended by the World Health Organization for neonatal sepsis is ampicillin and gentamicin, these findings indicate that updated guidelines should be considered [60]. Our genomic and sensitivity findings suggest that that ceftriaxone might be an alternative to ampicillin in those infections in which Paenibacillus is the suspected causative agent.

Of particular interest with regard to virulence of the clinical isolates, all three strains carry a 12$14 \mathrm{kbp}$ insertion with nearly identical organizations of all the genes necessary for a type IV pilus assembly, in linkage with genes for an AraC transcription regulator and the beta-lactamase ctype penicillin-binding protein (Fig 4A). Our proteomic analysis of the Mbale strain documented expression of genes in this operon (Table 3). Significantly, deletion of several genes within the operon substantially reduced the virulence of the Mbale strain according to pathogenesis test 
with our mouse model. This strongly suggests that the T4P system contributes to the pathogenesis of the clinical isolates.

T4P are thin bacterial appendages present in various bacteria, including several bacterial pathogens, and have been implicated in an array of functions including cellular adhesion [61, 62], cell mobility [63, 64], protein secretion [65], microcolony/biofilm formation [66-68] and horizontal gene transfer [69]. The T4P were initially observed exclusively in Gram negative bacteria but, with the advent of whole genome sequencing, many conserved components of the T4P have been identified and studied in Gram positive species [33, 70]. The T4P functions through cycles of major (PilA) and some minor pilin protein extension (polymerization) and retraction (depolymerization) driven by the cytoplasmic ATPase assembly pilB and pilT proteins respectively [71]. This cytoplasmic ATPase assembly is usually associated with the inner membrane protein PilC and aligned by the PilM, PilN and PilO proteins [71]. Prepilin (pilin) proteins in the structurally related type II secretion system are delivered to the periplasm via the general secretory (Sec) pathway [72] before being cleaved by the prepilin peptidase, PilD (Fig 3B). Accordingly, it is noteworthy that we observed expression of Sec pathway proteins in the clinical Mbale strain but not in the B-4156 strain. Finally, function of the pilus is often defined by the pilin protein structure, which has been characterized as IVa and IVb subtypes [73, 74]. The IVa T4P has generally been associated with eukaryotic cell adhesion $[61,62]$ and horizontal gene transfer [75] while the IVb pili promote self-adhesion [76, 77]. Accordingly, further study of the structure of the Mbale pilin protein will facilitate characterization of the function of the T4P of in P. thiaminolyticus and its role in pathogenesis. 
The T4P in our clinical isolates is closely related to those in Clostridium cellulolyticum $\mathrm{H} 10$ and Bacillus sp. NRRL B-14911 (Fig S4). The latter strain was originally isolated from the Gulf of Mexico [78] but was subsequently reclassified as Bacillus infantis [79]. Notably, B. infantis was isolated from a case of neonatal sepsis in Busan, South Korea [80], an observation that reinforces the possible connection of T4P and neonatal sepsis. Moreover, we noted that the PilB protein of our clinical isolates, but not that of the type strain, contains a c-di-GMP-binding motif domain

(Fig 4B). In C. perfringens, the formation of T4P is controlled in a c-di-GMP-dependent manner [81], which suggests the same might be true for the clinical isolates of $P$. thiaminolyticus. In Clostridioides difficile, increased c-di-GMP production of T4P promoted adherence to epithelial cells [82]. A detailed analysis in the regulation of T4P expression in clinical isolates of $P$. thiaminolyticus is expected to provide further insights into the potential contribution of c-diGMP to the virulence of the clinical isolates.

T4P is a widespread virulence factor that is structurally conserved, which makes it an attractive diagnostic and therapeutic target. Previously, Barnier et al [83] showed that the T4P mediated twitching motility by the PilT protein in the gram-negative pathogen Neisseria meningitis is required for sustained bacteremia. Moreover, they showed that adjunctive treatment with phenothiazines targeted T4P reduced vascular colonization and associated inflammation in a mouse model [84]. The impact of the phenothiazine family of drugs on the gram-positive T4P warrants further investigation and could provide a valuable adjunctive therapeutic approach to treatment of neonatal sepsis and PIH caused by P. thiaminolyticus. 
Successful pathogenic bacteria must propagate and survive within a host, which likely requires more that just one virulence factor. By identifying differences in the clinical strains, we have uncovered several candidate genes that may be involved in pathogenesis (Fig $2 \mathbf{A})$. However, focusing on only differences between the clinical isolates and type strain B-4156 may miss certain VFs, such as toxins, that could be present in both pathogenic and nonpathogenic bacteria but only mobilized in the former due inability of the nonpathogenic bacteria to survive in the host or to deliver the toxin $[65,77]$. For instance, our clinical isolates as well as the type strain encode a thiol-dependent cytolysin with $84 \%$ similarity to alveolysin, the toxin in Paenibacillus alvei that can lyse and inactivate eukaryotic cells [85-87]. Further functional genetic analysis of the clinical isolates will be required to identify additional relevant VFs. For instance, we demonstrated that comparative proteogenomic of differentially virulent bacterium of the same species can identify critical VFs that cannot be identified from annotation alone. Specifically, we pinpointed the T4P genes as critical for virulence in the clinical isolates of $P$. thiaminolyticus associated with PIH and NS and showed that they were acquired via a common MGE. This methodology thus provides an unbiased framework to identify key VFs in the bacterium that were previously unrecognized as a significant pathogen.

\section{Acknowledgments}

We thank the Penn State College of Medicine Genomics Core for Illumina sequencing of the bacteria and Dr. Yuka Imamura for her generosity in sharing equipment and materials for MinIon sequencing. We would also like to thank Dr. David Craft for his expertise and guidance on culturing and clinical evaluation of bacteria from clinical samples. The expert technical assistance of James Malone, Dr. Yiling Mi and Rose Connors is gratefully acknowledged. The 
proteomic experiments were performed at the Washington University Proteomics Shared

Resource (WU-PSR), R Reid Townsend MD.PhD., Director and Robert Sprung, PhD., Co-

Director). The WU-PSR is supported in part by the WU Institute of Clinical and Translational

Sciences (NCATS UL1 TR000448), the Mass Spectrometry Research Resource (NIGMS P41

GM103422; R24GM136766) and the Siteman Comprehensive Cancer Center Support Grant

(NCI P30 CA091842).

\section{Funding}

U.S. National Institutes of Health (N.I.H) Director's Pioneer Award 5DP1HD086071 and NIH

Director's Transformative Award 1R01AI145057. IT and MYG were supported by the

Intramural Research Program of the U.S. National Library of Medicine at the NIH. 


\section{References}

1. Dewan MC, Rattani A, Mekary R, Glancz LJ, Yunusa I, Baticulon RE, et al. Global hydrocephalus epidemiology and incidence: systematic review and meta-analysis. J Neurosurg. 2018:1-15. Epub 2018/04/28. doi: 10.3171/2017.10.JNS17439. PubMed PMID: 29701543.

2. Isaacs AM, Riva-Cambrin J, Yavin D, Hockley A, Pringsheim TM, Jette N, et al. Agespecific global epidemiology of hydrocephalus: Systematic review, metanalysis and global birth surveillance. PLoS One. 2018;13(10):e0204926. Epub 2018/10/03. doi:

10.1371/journal.pone.0204926. PubMed PMID: 30273390; PubMed Central PMCID: PMCPMC6166961.

3. Warf BC. Hydrocephalus in Uganda: the predominance of infectious origin and primary management with endoscopic third ventriculostomy. Journal of neurosurgery. 2005;102(1 Suppl):1-15. doi: 10.3171/ped.2005.102.1.0001.

4. Warf BC, East African Neurosurgical Research C. Pediatric hydrocephalus in East Africa: prevalence, causes, treatments, and strategies for the future. World Neurosurg. 2010;73(4):296-300. Epub 2010/09/21. doi: 10.1016/j.wneu.2010.02.009. PubMed PMID: 20849782.

5. Kulkarni AV, Schiff SJ, Mbabazi-Kabachelor E, Mugamba J, Ssenyonga P, Donnelly R, et al. Endoscopic Treatment versus Shunting for Infant Hydrocephalus in Uganda. N Engl J Med. 2017;377(25):2456-64. doi: 10.1056/NEJMoa1707568. PubMed PMID: 29262276.

6. Warf BC, Alkire BC, Bhai S, Hughes C, Schiff SJ, Vincent JR, et al. Costs and benefits of neurosurgical intervention for infant hydrocephalus in sub-Saharan Africa. Journal of neurosurgery Pediatrics. 2011;8(5):509-21. doi: 10.3171/2011.8.PEDS11163. 
7. Sinnar SA, Schiff SJ. The Problem of Microbial Dark Matter in Neonatal Sepsis. Emerg Infect Dis. 2020;26(11):2543-8. doi: 10.3201/eid2611.200004. PubMed PMID: 33080169;

PubMed Central PMCID: PMCPMC7588532.

8. Karimy JK, Reeves BC, Damisah E, Duy PQ, Antwi P, David W, et al. Inflammation in acquired hydrocephalus: pathogenic mechanisms and therapeutic targets. Nat Rev Neurol. 2020;16(5):285-96. Epub 2020/03/11. doi: 10.1038/s41582-020-0321-y. PubMed PMID:

32152460; PubMed Central PMCID: PMCPMC7375440.

9. Vinchon M, Rekate H, Kulkarni AV. Pediatric hydrocephalus outcomes: a review. Fluids Barriers CNS. 2012;9(1):18. Epub 2012/08/29. doi: 10.1186/2045-8118-9-18. PubMed PMID: 22925451 ; PubMed Central PMCID: PMCPMC3584674.

10. Kiwanuka J, Bazira J, Mwanga J, Tumusiime D, Nyesigire E, Lwanga N, et al. The Microbial Spectrum of Neonatal Sepsis in Uganda: Recovery of Culturable Bacteria in MotherInfant Pairs. PLoS ONE. 2013;8(8):e72775-e. doi: 10.1371/journal.pone.0072775.t004.

11. Li L, Padhi A, Ranjeva SL, Donaldson SC, Warf BC, Mugamba J, et al. Association of bacteria with hydrocephalus in Ugandan infants. J Neurosurg Pediatr. 2011;7(1):73-87. doi: 10.3171/2010.9.PEDS10162. PubMed PMID: 21194290.

12. Schiff SJ, Kiwanuka J, Riggio G, Nguyen L, Mu K, Sproul E, et al. Separating Putative Pathogens from Background Contamination with Principal Orthogonal Decomposition: Evidence for Leptospira in the Ugandan Neonatal Septisome. Front Med (Lausanne). 2016;3:22. Epub 2016/07/06. doi: 10.3389/fmed.2016.00022. PubMed PMID: 27379237; PubMed Central PMCID: PMCPMC4904006. 
13. Paulson J, Williams BL, Hehnly C, Sinnar S, Zhang L, ssentongo P, et al. The Bacterial and Viral Complexity of Infant Postinfectious Hydrocephalus in Uganda. Sci Transl Med. 2020;12(563):1-12. doi: 10.1126/scitranslmed.aba0565.

14. Grady EN, MacDonald J, Liu L, Richman A, Yuan ZC. Current knowledge and perspectives of Paenibacillus: a review. Microb Cell Fact. 2016;15(1):203. Epub 20161201. doi: 10.1186/s12934-016-0603-7. PubMed PMID: 27905924; PubMed Central PMCID:

\section{PMCPMC5134293.}

15. Genersch E. American Foulbrood in honeybees and its causative agent, Paenibacillus larvae. J Invertebr Pathol. 2010;103 Suppl 1:S10-9. Epub 20091111. doi:

10.1016/j.jip.2009.06.015. PubMed PMID: 19909971.

16. DeLeon SD, Welliver RC, Sr. Paenibacillus alvei Sepsis in a Neonate. Pediatr Infect Dis J. 2016;35(3):358. doi: 10.1097/INF.0000000000001003. PubMed PMID: 26866854.

17. Hunt B, Rogers C, Blais RM, Adachi K, Sathyavagiswaran L. Paenibacillus Sepsis and Meningitis in a Premature Infant: A Case Report. Am J Forensic Med Pathol. 2021;42(1):96-8. doi: 10.1097/PAF.0000000000000610. PubMed PMID: 32852292.

18. Leao RS, Pereira RH, Ferreira AG, Lima AN, Albano RM, Marques EA. First report of Paenibacillus cineris from a patient with cystic fibrosis. Diagn Microbiol Infect Dis. 2010;66(1):101-3. Epub 20090825. doi: 10.1016/j.diagmicrobio.2009.06.011. PubMed PMID: 19709843.

19. Ouyang J, Pei Z, Lutwick L, Dalal S, Yang L, Cassai N, et al. Case report: Paenibacillus thiaminolyticus: a new cause of human infection, inducing bacteremia in a patient on hemodialysis. Ann Clin Lab Sci. 2008;38(4):393-400. PubMed PMID: 18988935. 
20. Quenard F, Aubry C, Palmieri M, Edouard S, Parola P, Lagier JC. First case of bone infection caused by Paenibacillus turicensis. New Microbes New Infect. 2016;11:45-6. Epub 20160223. doi: 10.1016/j.nmni.2016.02.004. PubMed PMID: 27257492; PubMed Central PMCID: PMCPMC4877404.

21. Saez-Nieto JA, Medina-Pascual MJ, Carrasco G, Garrido N, Fernandez-Torres MA, Villalon P, et al. Paenibacillus spp. isolated from human and environmental samples in Spain: detection of 11 new species. New Microbes New Infect. 2017;19:19-27. Epub 20170524. doi: 10.1016/j.nmni.2017.05.006. PubMed PMID: 28702198; PubMed Central PMCID:

\section{PMCPMC5484988.}

22. Hehnly C, Zhang L, Paulson JN, Almeida M, von Bredow B, Wijetunge DSS, et al. Complete Genome Sequences of the Human Pathogen Paenibacillus thiaminolyticus Mbale and Type Strain P. thiaminolyticus NRRL B-4156. Microbiol Resour Announc. 2020;9(15). Epub 2020/04/11. doi: 10.1128/MRA.00181-20. PubMed PMID: 32273361; PubMed Central PMCID: PMCPMC7380522.

23. Koren S, Walenz BP, Berlin K, Miller JR, Bergman NH, Phillippy AM. Canu: scalable and accurate long-read assembly via adaptive k-mer weighting and repeat separation. Genome Res. 2017;27(5):722-36. Epub 2017/03/17. doi: 10.1101/gr.215087.116. PubMed PMID: 28298431 ; PubMed Central PMCID: PMCPMC5411767.

24. Walker BJ, Abeel T, Shea T, Priest M, Abouelliel A, Sakthikumar S, et al. Pilon: an integrated tool for comprehensive microbial variant detection and genome assembly improvement. PLoS One. 2014;9(11):e112963. Epub 20141119. doi: 10.1371/journal.pone.0112963. PubMed PMID: 25409509; PubMed Central PMCID: PMCPMC4237348. 
25. Li W, O'Neill KR, Haft DH, DiCuccio M, Chetvernin V, Badretdin A, et al. RefSeq: expanding the Prokaryotic Genome Annotation Pipeline reach with protein family model curation. Nucleic Acids Res. 2021;49(D1):D1020-D8. doi: 10.1093/nar/gkaa1 105. PubMed PMID: 33270901; PubMed Central PMCID: PMCPMC7779008.

26. Tatusova T, DiCuccio M, Badretdin A, Chetvernin V, Nawrocki EP, Zaslavsky L, et al. NCBI prokaryotic genome annotation pipeline. Nucleic Acids Res. 2016;44(14):6614-24. Epub 20160624. doi: 10.1093/nar/gkw569. PubMed PMID: 27342282; PubMed Central PMCID: PMCPMC5001611.

27. Brettin T, Davis JJ, Disz T, Edwards RA, Gerdes S, Olsen GJ, et al. RASTtk: a modular and extensible implementation of the RAST algorithm for building custom annotation pipelines and annotating batches of genomes. Sci Rep. 2015;5:8365. Epub 20150210. doi:

10.1038/srep08365. PubMed PMID: 25666585; PubMed Central PMCID: PMCPMC4322359. 28. Davis JJ, Wattam AR, Aziz RK, Brettin T, Butler R, Butler RM, et al. The PATRIC Bioinformatics Resource Center: expanding data and analysis capabilities. Nucleic Acids Res. 2020;48(D1):D606-D12. doi: 10.1093/nar/gkz943. PubMed PMID: 31667520; PubMed Central PMCID: PMCPMC7145515.

29. Stothard P, Grant JR, Van Domselaar G. Visualizing and comparing circular genomes using the CGView family of tools. Brief Bioinform. 2019;20(4):1576-82. doi:

10.1093/bib/bbx081. PubMed PMID: 28968859; PubMed Central PMCID: PMCPMC6781573.

30. Xu L, Dong Z, Fang L, Luo Y, Wei Z, Guo H, et al. OrthoVenn2: a web server for whole-genome comparison and annotation of orthologous clusters across multiple species. Nucleic Acids Res. 2019;47(W1):W52-W8. doi: 10.1093/nar/gkz333. PubMed PMID: 31053848; PubMed Central PMCID: PMCPMC6602458. 
31. Wickham H, SpringerLink. ggplot2 : Elegant Graphics for Data Analysis. 1st 2009. ed.

New York, NY: Springer New York : Imprint: Springer; 2009.

32. Goris J, Konstantinidis KT, Klappenbach JA, Coenye T, Vandamme P, Tiedje JM. DNADNA hybridization values and their relationship to whole-genome sequence similarities. Int J Syst Evol Microbiol. 2007;57(Pt 1):81-91. Epub 2007/01/16. doi: 10.1099/ijs.0.64483-0.

PubMed PMID: 17220447.

33. Imam S, Chen Z, Roos DS, Pohlschroder M. Identification of surprisingly diverse type IV pili, across a broad range of gram-positive bacteria. PLoS One. 2011;6(12):e28919. Epub 20111221. doi: 10.1371/journal.pone.0028919. PubMed PMID: 22216142; PubMed Central PMCID: PMCPMC3244431.

34. Arndt D, Grant JR, Marcu A, Sajed T, Pon A, Liang Y, et al. PHASTER: a better, faster version of the PHAST phage search tool. Nucleic Acids Res. 2016;44(W1):W16-21. Epub 20160503. doi: 10.1093/nar/gkw387. PubMed PMID: 27141966; PubMed Central PMCID: PMCPMC4987931.

35. Love MI, Huber W, Anders S. Moderated estimation of fold change and dispersion for RNA-seq data with DESeq2. Genome Biol. 2014;15(12):550. doi: 10.1186/s13059-014-0550-8. PubMed PMID: 25516281; PubMed Central PMCID: PMCPMC4302049.

36. Chen ZW, Fuchs K, Sieghart W, Townsend RR, Evers AS. Deep amino acid sequencing of native brain GABAA receptors using high-resolution mass spectrometry. Mol Cell Proteomics. 2012;11(1):M111 011445. Epub 2012/02/18. PubMed PMID: 22338125; PubMed Central PMCID: PMCPMC3270104. 
37. Wisniewski JR, Zougman A, Nagaraj N, Mann M. Universal sample preparation method for proteome analysis. Nat Methods. 2009;6(5):359-62. Epub 20090419. doi: 10.1038/nmeth.1322. PubMed PMID: 19377485.

38. Ma B, Zhang K, Hendrie C, Liang C, Li M, Doherty-Kirby A, et al. PEAKS: powerful software for peptide de novo sequencing by tandem mass spectrometry. Rapid Commun Mass Spectrom. 2003;17(20):2337-42. doi: 10.1002/rcm.1196. PubMed PMID: 14558135.

39. Toymentseva AA, Altenbuchner J. New CRISPR-Cas9 vectors for genetic modifications of Bacillus species. FEMS Microbiol Lett. 2019;366(1). Epub 2018/12/07. doi:

10.1093/femsle/fny284. PubMed PMID: 30520985.

40. Altenbuchner J. Editing of the Bacillus subtilis Genome by the CRISPR-Cas9 System. Appl Environ Microbiol. 2016;82(17):5421-7. Epub 2016/06/28. doi: 10.1128/AEM.01453-16. PubMed PMID: 27342565; PubMed Central PMCID: PMCPMC4988203.

41. Rodriguez RL, Gunturu S, Harvey WT, Rossello-Mora R, Tiedje JM, Cole JR, et al. The Microbial Genomes Atlas (MiGA) webserver: taxonomic and gene diversity analysis of Archaea and Bacteria at the whole genome level. Nucleic Acids Res. 2018;46(W1):W282-W8. Epub 2018/06/16. doi: 10.1093/nar/gky467. PubMed PMID: 29905870; PubMed Central PMCID: PMCPMC6031002.

42. Darling AC, Mau B, Blattner FR, Perna NT. Mauve: multiple alignment of conserved genomic sequence with rearrangements. Genome Res. 2004;14(7):1394-403. doi: 10.1101/gr.2289704. PubMed PMID: 15231754; PubMed Central PMCID: PMCPMC442156. 43. Hsiao WW, Ung K, Aeschliman D, Bryan J, Finlay BB, Brinkman FS. Evidence of a large novel gene pool associated with prokaryotic genomic islands. PLoS Genet. 2005;1(5):e62. 
Epub 20051118. doi: 10.1371/journal.pgen.0010062. PubMed PMID: 16299586; PubMed Central PMCID: PMCPMC1285063.

44. Perna NT, Plunkett G, 3rd, Burland V, Mau B, Glasner JD, Rose DJ, et al. Genome sequence of enterohaemorrhagic Escherichia coli O157:H7. Nature. 2001;409(6819):529-33. doi: 10.1038/35054089. PubMed PMID: 11206551.

45. Durrant MG, Li MM, Siranosian BA, Montgomery SB, Bhatt AS. A Bioinformatic Analysis of Integrative Mobile Genetic Elements Highlights Their Role in Bacterial Adaptation. Cell Host Microbe. 2020;27(1):140-53 e9. Epub 20191217. doi: 10.1016/j.chom.2019.10.022. PubMed PMID: 31862382; PubMed Central PMCID: PMCPMC6952549.

46. Melville S, Craig L. Type IV pili in Gram-positive bacteria. Microbiol Mol Biol Rev. 2013;77(3):323-41. doi: 10.1128/MMBR.00063-12. PubMed PMID: 24006467; PubMed Central PMCID: PMCPMC3811610.

47. Galperin MY, Wolf YI, Makarova KS, Vera Alvarez R, Landsman D, Koonin EV. COG database update: focus on microbial diversity, model organisms, and widespread pathogens. Nucleic Acids Res. 2021;49(D1):D274-D81. doi: 10.1093/nar/gkaa1018. PubMed PMID: 33167031; PubMed Central PMCID: PMCPMC7778934.

48. Mistry J, Chuguransky S, Williams L, Qureshi M, Salazar GA, Sonnhammer ELL, et al. Pfam: The protein families database in 2021. Nucleic Acids Res. 2021;49(D1):D412-D9. doi: 10.1093/nar/gkaa913. PubMed PMID: 33125078; PubMed Central PMCID: PMCPMC7779014. 49. Chernyatina AA, Low HH. Core architecture of a bacterial type II secretion system. Nat Commun. 2019;10(1):5437. Epub 20191128. doi: 10.1038/s41467-019-13301-3. PubMed PMID: 31780649; PubMed Central PMCID: PMCPMC6882859. 
50. Filloux A. The underlying mechanisms of type II protein secretion. Biochim Biophys Acta. 2004;1694(1-3):163-79. doi: 10.1016/j.bbamcr.2004.05.003. PubMed PMID: 15546665.

51. Pugsley AP, Francetic O, Possot OM, Sauvonnet N, Hardie KR. Recent progress and future directions in studies of the main terminal branch of the general secretory pathway in Gram-negative bacteria--a review. Gene. 1997;192(1):13-9. doi: 10.1016/s0378-1119(96)008037. PubMed PMID: 9224869.

52. Gurung I, Spielman I, Davies MR, Lala R, Gaustad P, Biais N, et al. Functional analysis of an unusual type IV pilus in the Gram-positive Streptococcus sanguinis. Mol Microbiol. 2016;99(2):380-92. Epub 20151027. doi: 10.1111/mmi.13237. PubMed PMID: 26435398; PubMed Central PMCID: PMCPMC4832360.

53. Soncini SR, Hartman AH, Gallagher TM, Camper GJ, Jensen RV, Melville SB. Changes in the expression of genes encoding type IV pili-associated proteins are seen when Clostridium perfringens is grown in liquid or on surfaces. BMC Genomics. 2020;21(1):45. Epub 20200114. doi: 10.1186/s12864-020-6453-z. PubMed PMID: 31937237; PubMed Central PMCID: PMCPMC6958937.

54. Wang YC, Chin KH, Tu ZL, He J, Jones CJ, Sanchez DZ, et al. Nucleotide binding by the widespread high-affinity cyclic di-GMP receptor MshEN domain. Nat Commun. 2016;7:12481. Epub 20160831. doi: 10.1038/ncomms 12481. PubMed PMID: 27578558; PubMed Central PMCID: PMCPMC5013675.

55. Ash C, Priest FG, Collins MD. Molecular identification of rRNA group 3 bacilli (Ash, Farrow, Wallbanks and Collins) using a PCR probe test. Proposal for the creation of a new genus Paenibacillus. Antonie Van Leeuwenhoek. 1993;64(3-4):253-60. Epub 1993/01/01. PubMed PMID: 8085788. 
56. Shida O, Takagi H, Kadowaki K, Nakamura LK, Komagata K. Transfer of Bacillus alginolyticus, Bacillus chondroitinus, Bacillus curdlanolyticus, Bacillus glucanolyticus, Bacillus kobensis, and Bacillus thiaminolyticus to the genus Paenibacillus and emended description of the genus Paenibacillus. Int J Syst Bacteriol. 1997;47(2):289-98. doi: 10.1099/00207713-47-2-289. PubMed PMID: 9103612.

57. De Vos P, Ludwig W, Schleifer K-H, Whitman WB. Family IV. Paenibacillus. In: De Vos P, Garrity G, Jones D, Kreig NR, Ludwig W, Rainey FA, et al., editors. Bergey's Manual of Systematic Bacteriology: Volume 3: The Firmicutes. 3. Dordrecht, Heidelberg, London, New York: Springer-Verlag; 2009. p. 269-327.

58. Gallegos MT, Schleif R, Bairoch A, Hofmann K, Ramos JL. Arac/XylS family of transcriptional regulators. Microbiol Mol Biol Rev. 1997;61(4):393-410. doi:

10.1128/mmbr.61.4.393-410.1997. PubMed PMID: 9409145; PubMed Central PMCID: PMCPMC232617.

59. Martin RG, Rosner JL. The AraC transcriptional activators. Curr Opin Microbiol. 2001;4(2):132-7. doi: 10.1016/s1369-5274(00)00178-8. PubMed PMID: 11282467.

60. Fuchs A, Bielicki J, Mathur S, Sharland M, Van Den Anker JN. Reviewing the WHO guidelines for antibiotic use for sepsis in neonates and children. Paediatr Int Child Health. 2018;38(sup1):S3-S15. doi: 10.1080/20469047.2017.1408738. PubMed PMID: 29790842; PubMed Central PMCID: PMCPMC6176768.

61. Farinha MA, Conway BD, Glasier LM, Ellert NW, Irvin RT, Sherburne R, et al. Alteration of the pilin adhesin of Pseudomonas aeruginosa PAO results in normal pilus biogenesis but a loss of adherence to human pneumocyte cells and decreased virulence in mice. 
Infect Immun. 1994;62(10):4118-23. doi: 10.1128/iai.62.10.4118-4123.1994. PubMed PMID:

7927665; PubMed Central PMCID: PMCPMC303085.

62. Parker D, Kennan RM, Myers GS, Paulsen IT, Songer JG, Rood JI. Regulation of type IV fimbrial biogenesis in Dichelobacter nodosus. J Bacteriol. 2006;188(13):4801-11. doi:

10.1128/JB.00255-06. PubMed PMID: 16788189; PubMed Central PMCID: PMCPMC1483018.

63. Bradley DE. A function of Pseudomonas aeruginosa PAO polar pili: twitching motility.

Can J Microbiol. 1980;26(2):146-54. doi: 10.1139/m80-022. PubMed PMID: 6105908.

64. Whitchurch CB, Hobbs M, Livingston SP, Krishnapillai V, Mattick JS. Characterisation of a Pseudomonas aeruginosa twitching motility gene and evidence for a specialised protein export system widespread in eubacteria. Gene. 1991;101(1):33-44. doi: 10.1016/03781119(91)90221-v. PubMed PMID: 1676385.

65. Kirn TJ, Bose N, Taylor RK. Secretion of a soluble colonization factor by the TCP type 4 pilus biogenesis pathway in Vibrio cholerae. Mol Microbiol. 2003;49(1):81-92. doi:

10.1046/j.1365-2958.2003.03546.x. PubMed PMID: 12823812.

66. Jurcisek JA, Bookwalter JE, Baker BD, Fernandez S, Novotny LA, Munson RS, Jr., et al. The PilA protein of non-typeable Haemophilus influenzae plays a role in biofilm formation, adherence to epithelial cells and colonization of the mammalian upper respiratory tract. Mol Microbiol. 2007;65(5):1288-99. Epub 20070723. doi: 10.1111/j.1365-2958.2007.05864.x. PubMed PMID: 17645732.

67. Klausen M, Heydorn A, Ragas P, Lambertsen L, Aaes-Jorgensen A, Molin S, et al. Biofilm formation by Pseudomonas aeruginosa wild type, flagella and type IV pili mutants. Mol Microbiol. 2003;48(6):1511-24. doi: 10.1046/j.1365-2958.2003.03525.x. PubMed PMID: 12791135. 
68. Shime-Hattori A, lida T, Arita M, Park KS, Kodama T, Honda T. Two type IV pili of Vibrio parahaemolyticus play different roles in biofilm formation. FEMS Microbiol Lett. 2006;264(1):89-97. doi: 10.1111/j.1574-6968.2006.00438.x. PubMed PMID: 17020553.

69. Harding CM, Tracy EN, Carruthers MD, Rather PN, Actis LA, Munson RS, Jr. Acinetobacter baumannii strain M2 produces type IV pili which play a role in natural transformation and twitching motility but not surface-associated motility. mBio. 2013;4(4). Epub 20130806. doi: 10.1128/mBio.00360-13. PubMed PMID: 23919995; PubMed Central PMCID: PMCPMC3735195.

70. Muschiol S, Aschtgen MS, Nannapaneni P, Henriques-Normark B. Gram-Positive Type IV Pili and Competence. Microbiol Spectr. 2019;7(1). doi: 10.1128/microbiolspec.PSIB-00112018. PubMed PMID: 30737914.

71. Chang YW, Rettberg LA, Treuner-Lange A, Iwasa J, Sogaard-Andersen L, Jensen GJ. Architecture of the type IVa pilus machine. Science. 2016;351(6278):aad2001. Epub 20160310. doi: 10.1126/science.aad2001. PubMed PMID: 26965631; PubMed Central PMCID: PMCPMC5929464.

72. Pugsley AP. The complete general secretory pathway in gram-negative bacteria. Microbiol Rev. 1993;57(1):50-108. doi: 10.1128/mr.57.1.50-108.1993. PubMed PMID: 8096622; PubMed Central PMCID: PMCPMC372901.

73. Piepenbrink KH, Sundberg EJ. Motility and adhesion through type IV pili in Grampositive bacteria. Biochem Soc Trans. 2016;44(6):1659-66. Epub 2016/12/04. doi:

10.1042/BST20160221. PubMed PMID: 27913675; PubMed Central PMCID: PMCPMC5830096. 
74. Giltner CL, Nguyen Y, Burrows LL. Type IV pilin proteins: versatile molecular modules. Microbiol Mol Biol Rev. 2012;76(4):740-72. Epub 2012/12/04. doi: 10.1128/MMBR.00035-12. PubMed PMID: 23204365.

75. Aas FE, Winther-Larsen HC, Wolfgang M, Frye S, Lovold C, Roos N, et al. Substitutions in the N-terminal alpha helical spine of Neisseria gonorrhoeae pilin affect Type IV pilus assembly, dynamics and associated functions. Mol Microbiol. 2007;63(1):69-85. Epub 20061127. doi: 10.1111/j.1365-2958.2006.05482.x. PubMed PMID: 17140412.

76. Anantha RP, Stone KD, Donnenberg MS. Effects of bfp mutations on biogenesis of functional enteropathogenic Escherichia coli type IV pili. J Bacteriol. 2000;182(9):2498-506. doi: 10.1128/JB.182.9.2498-2506.2000. PubMed PMID: 10762251; PubMed Central PMCID: PMCPMC111313.

77. Herrington DA, Hall RH, Losonsky G, Mekalanos JJ, Taylor RK, Levine MM. Toxin, toxin-coregulated pili, and the toxR regulon are essential for Vibrio cholerae pathogenesis in humans. J Exp Med. 1988;168(4):1487-92. doi: 10.1084/jem.168.4.1487. PubMed PMID: 2902187; PubMed Central PMCID: PMCPMC2189073.

78. Siefert JL, Larios-Sanz M, Nakamura LK, Slepecky RA, Paul JH, Moore ER, et al. Phylogeny of marine Bacillus isolates from the Gulf of Mexico. Curr Microbiol. 2000;41(2):848. doi: 10.1007/s002840010098. PubMed PMID: 10856371.

79. Massilamany C, Mohammed A, Loy JD, Purvis T, Krishnan B, Basavalingappa RH, et al. Whole genomic sequence analysis of Bacillus infantis: defining the genetic blueprint of strain NRRL B-14911, an emerging cardiopathogenic microbe. BMC Genomics. 2016;17 Suppl 7:511. Epub 20160822. doi: 10.1186/s12864-016-2900-2. PubMed PMID: 27557119; PubMed Central PMCID: PMCPMC5001198. 
80. Ko KS, Oh WS, Lee MY, Lee JH, Lee H, Peck KR, et al. Bacillus infantis sp. nov. and Bacillus idriensis sp. nov., isolated from a patient with neonatal sepsis. Int J Syst Evol Microbiol. 2006;56(Pt 11):2541-4. doi: 10.1099/ijs.0.64213-0. PubMed PMID: 17082387.

81. Hendrick WA, Orr MW, Murray SR, Lee VT, Melville SB. Cyclic Di-GMP Binding by an Assembly ATPase (PilB2) and Control of Type IV Pilin Polymerization in the Gram-Positive Pathogen Clostridium perfringens. J Bacteriol. 2017;199(10). Epub 20170425. doi:

10.1128/JB.00034-17. PubMed PMID: 28242722; PubMed Central PMCID: PMCPMC5405213. 82. McKee RW, Aleksanyan N, Garrett EM, Tamayo R. Type IV Pili Promote Clostridium difficile Adherence and Persistence in a Mouse Model of Infection. Infect Immun. 2018;86(5). Epub 20180423. doi: 10.1128/IAI.00943-17. PubMed PMID: 29483294; PubMed Central PMCID: PMCPMC5913833.

83. Barnier JP, Euphrasie D, Join-Lambert O, Audry M, Schonherr-Hellec S, Schmitt T, et al. Type IV pilus retraction enables sustained bacteremia and plays a key role in the outcome of meningococcal sepsis in a humanized mouse model. PLoS Pathog. 2021;17(2):e1009299. Epub 20210216. doi: 10.1371/journal.ppat.1009299. PubMed PMID: 33592056; PubMed Central PMCID: PMCPMC7909687.

84. Denis K, Le Bris M, Le Guennec L, Barnier JP, Faure C, Gouge A, et al. Targeting Type IV pili as an antivirulence strategy against invasive meningococcal disease. Nat Microbiol. 2019;4(6):972-84. Epub 20190325. doi: 10.1038/s41564-019-0395-8. PubMed PMID: 30911127.

85. Bremm KD, Konig W, Pfeiffer P, Rauschen I, Theobald K, Thelestam M, et al. Effect of thiol-activated toxins (streptolysin $\mathrm{O}$, alveolysin, and theta toxin) on the generation of leukotrienes and leukotriene-inducing and -metabolizing enzymes from human 
polymorphonuclear granulocytes. Infect Immun. 1985;50(3):844-51. doi: 10.1128/iai.50.3.844-

851.1985. PubMed PMID: 2866160; PubMed Central PMCID: PMCPMC261157.

86. Geoffroy C, Mengaud J, Alouf JE, Cossart P. Alveolysin, the thiol-activated toxin of

Bacillus alvei, is homologous to listeriolysin $\mathrm{O}$, perfringolysin $\mathrm{O}$, pneumolysin, and streptolysin

O and contains a single cysteine. J Bacteriol. 1990;172(12):7301-5. doi: 10.1128/jb.172.12.7301-

7305.1990. PubMed PMID: 2254290; PubMed Central PMCID: PMCPMC210863.

87. Thelestam M, Alouf JE, Geoffroy C, Mollby R. Membrane-damaging action of

alveolysin from Bacillus alvei. Infect Immun. 1981;32(3):1187-92. doi: 10.1128/iai.32.3.1187-

1192.1981. PubMed PMID: 6894743; PubMed Central PMCID: PMCPMC351577.

88. Duvel J, Bense S, Moller S, Bertinetti D, Schwede F, Morr M, et al. Application of

Synthetic Peptide Arrays To Uncover Cyclic Di-GMP Binding Motifs. J Bacteriol.

2016;198(1):138-46. Epub 2015/09/02. doi: 10.1128/JB.00377-15. PubMed PMID: 26324453;

PubMed Central PMCID: PMCPMC4686192.

89. Lantos PM, Hoffman K, Permar SR, Jackson P, Hughes BL, Swamy GK. Geographic

Disparities in Cytomegalovirus Infection During Pregnancy. Journal of the Pediatric Infectious

Diseases Society. 2017;6(3):e55-e61. doi: 10.1093/jpids/piw088. PubMed PMID: 28201739.

90. Junkermeier EH, Hengge R. A novel locally c-di-GMP-controlled exopolysaccharide synthase required for N4 phage infection of $<$ em $>$ E. coli $</$ em $>$. bioRxiv.

2021:2021.10.01.462733. doi: 10.1101/2021.10.01.462733.

91. Sellner B, Prakapaitè R, van Berkum M, Heinemann M, Harms A, Jenal U. A new sugar for an old phage: A c-di-GMP dependent polysaccharide pathway sensitizes $<$ em $>$ E. coli $</$ em $>$ for bacteriophage infection. bioRxiv. 2021:2021.09.27.461960. doi: 10.1101/2021.09.27.461960. 
92. Roelofs KG, Jones CJ, Helman SR, Shang X, Orr MW, Goodson JR, et al. Systematic Identification of Cyclic-di-GMP Binding Proteins in Vibrio cholerae Reveals a Novel Class of Cyclic-di-GMP-Binding ATPases Associated with Type II Secretion Systems. PLoS Pathog. 2015;11(10):e1005232. Epub 2015/10/28. doi: 10.1371/journal.ppat.1005232. PubMed PMID: 26506097; PubMed Central PMCID: PMCPMC4624772. 


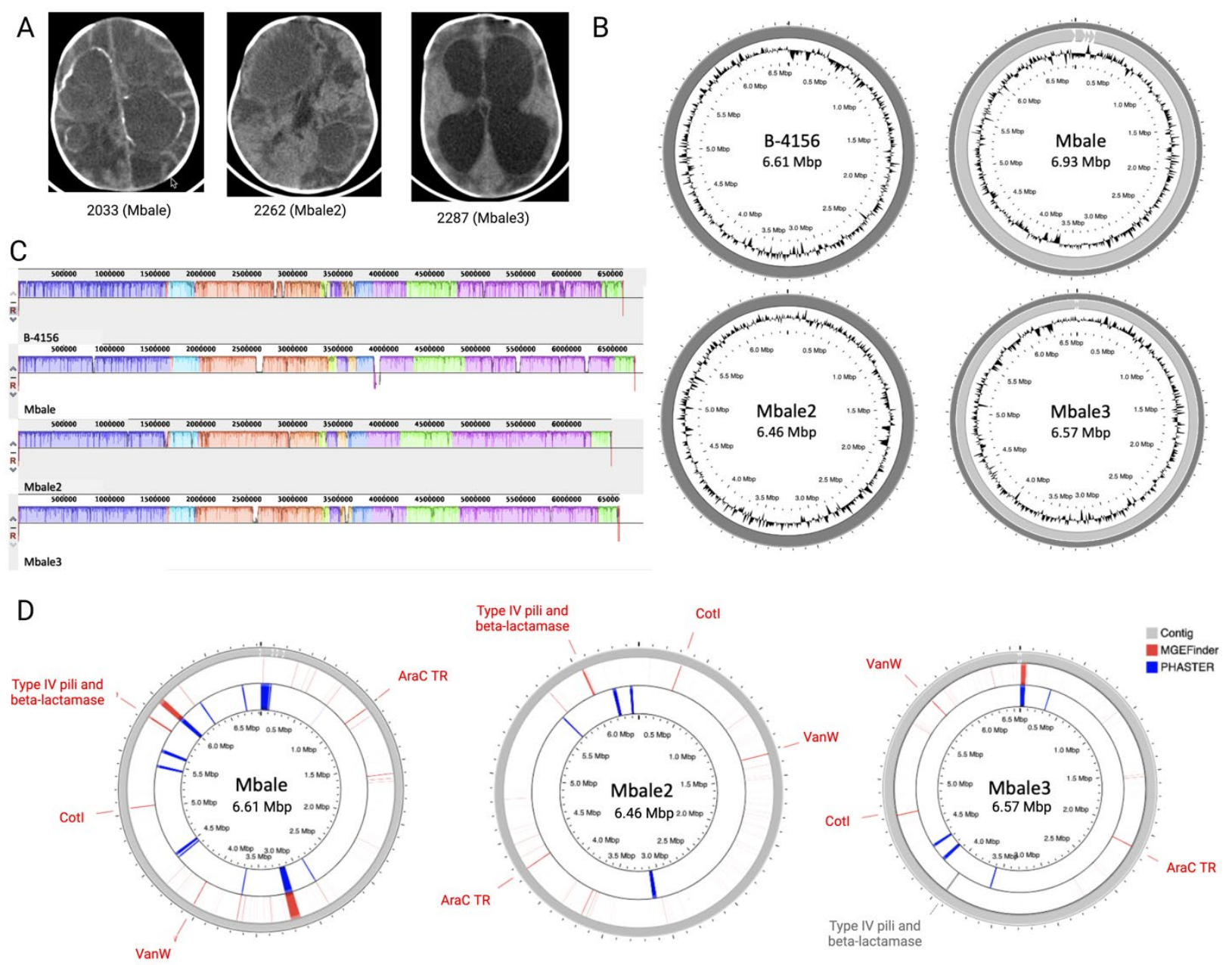

Figure 1. Genomic Characterization of Clinical Isolates of P. thiaminolyticus.

A) Computerized tomography scans from the three infants with postinfectious hydrocephalus from whose cerebrospinal fluid (CSF) the three clinical isolates were recovered. The first two images from 2033 (clinical isolate strain Mbale) and 2262 (clinical isolate strain Mbale2) were taken prior to surgery and demonstrate loculations and calcified abscess formation. The third image from 2287 (clinical isolate strain Mbale3) was taken after surgery for hydrocephalus and also shows evidence of extensive brain parenchyma damage. B) Shown are complete assemblies of the type strain of $P$. thiaminlytocus B-4156 ${ }^{\mathrm{T}}$ (B-4156) and three clinical isolates Mbale, Mbale2, and Mbale3, obtained using long and short-read sequencing. The B-4156 and Mbale3 
genomes each consists of one continuous contig while the Mbale and Mbale2 genomes each comprises one large contig plus additional contigs (Table 1). C) Alignment with MAUVE of the clinical isolates' genomes to that of the B-4156 type strain identified twelve locally colinear blocks (LCB), which are indicated by the different colors. White regions within the colored regions represent regions of low sequence similarity. D) Mobile genetic element finder (MGEFinder) identified regions of genomes that could have been derived from mobile genetic elements (MGE, red bars) and could account for the regions of low sequence similarity. Genes specified in red were identified by RAST as being encoded in the predicted MGEs and include the antibiotic-resistant vancomycin gene (VanW), spore coat protein (CotI) and an arabinose family transcription regulator (AraC). Furthermore, a predicted MGE in Mbale and Mbale2 encoded an operon for the type IV pilus, which, although not predicted to be an MGE in Mbale3, was also present in that genome (gray). Regions of phage sequences, identified by PHASTER, are labeled in blue. 

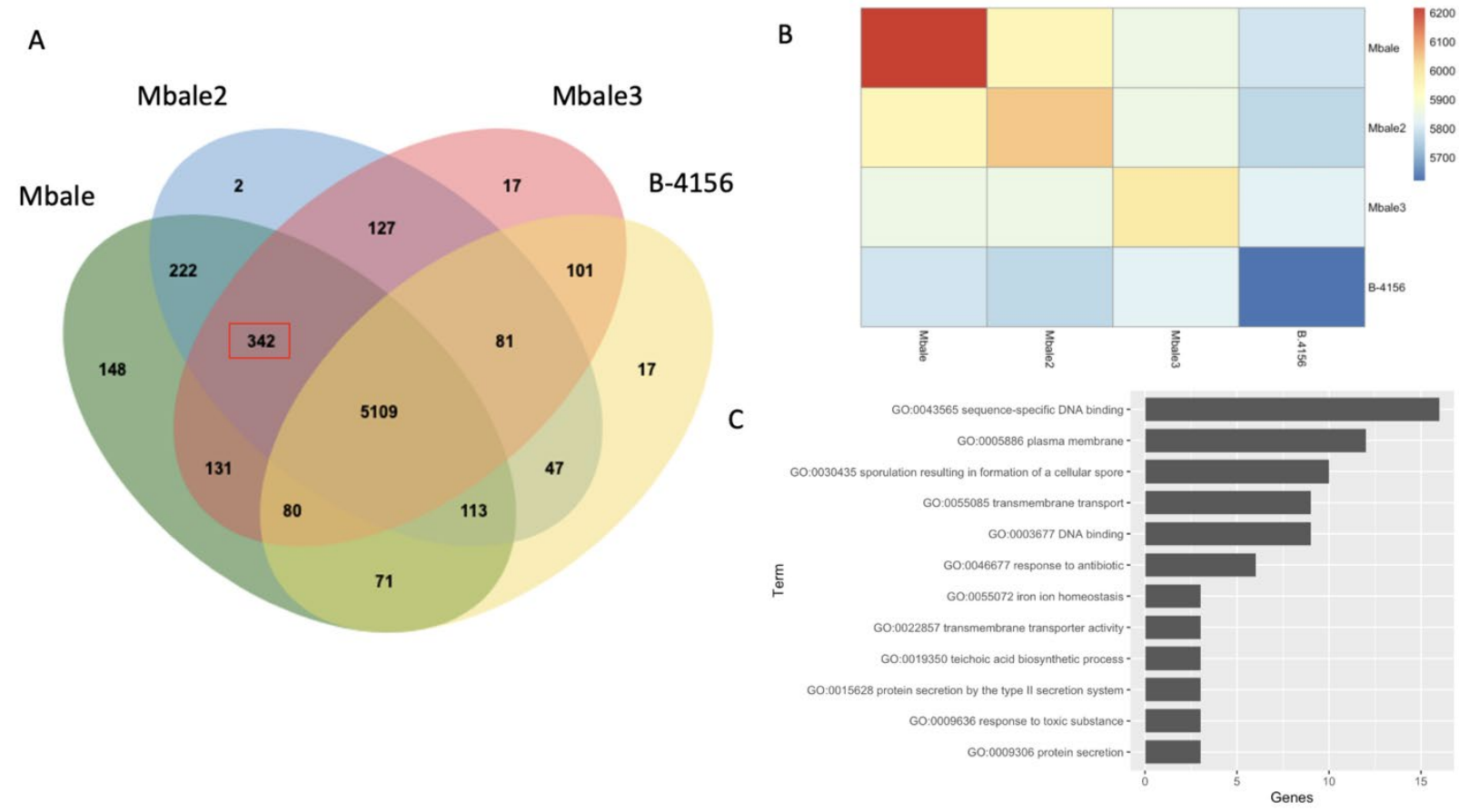

Figure 2. Comparisons of the Predicted Proteomes of the Clinical Isolates and the type

strain A) Venn diagram from OrthoVenn2 analysis comparing the four annotations of the B4156, Mbale, Mbale2, and Mbale3 strains. The 342 paralogous clusters among the clinical isolates that were absent in the nonpathogenic B-4156 are outlined in red. B) A heatmap quantifying the predicted paralogous clusters across each isolate. C) Clinically relevant gene ontology terms from the 342 proteins that were unique to the clinical isolates. 


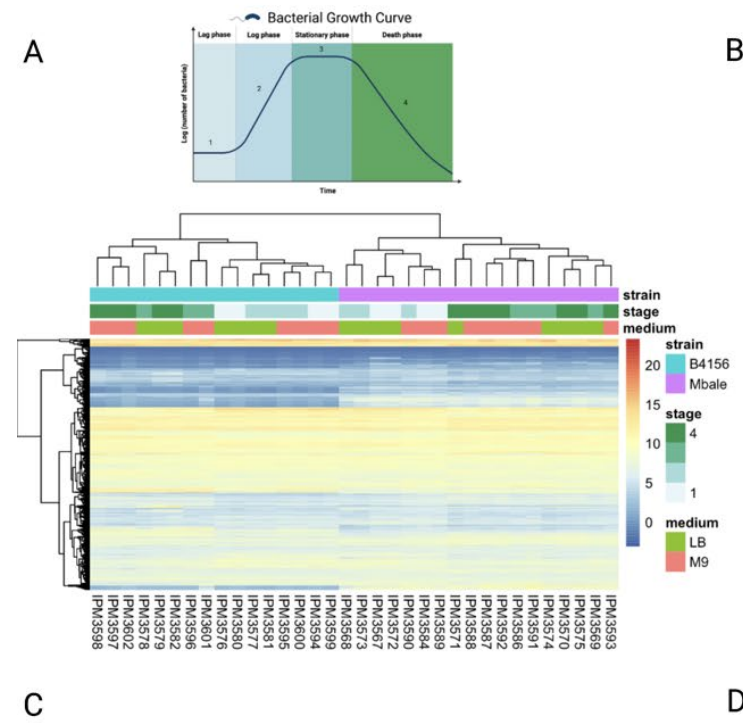

B
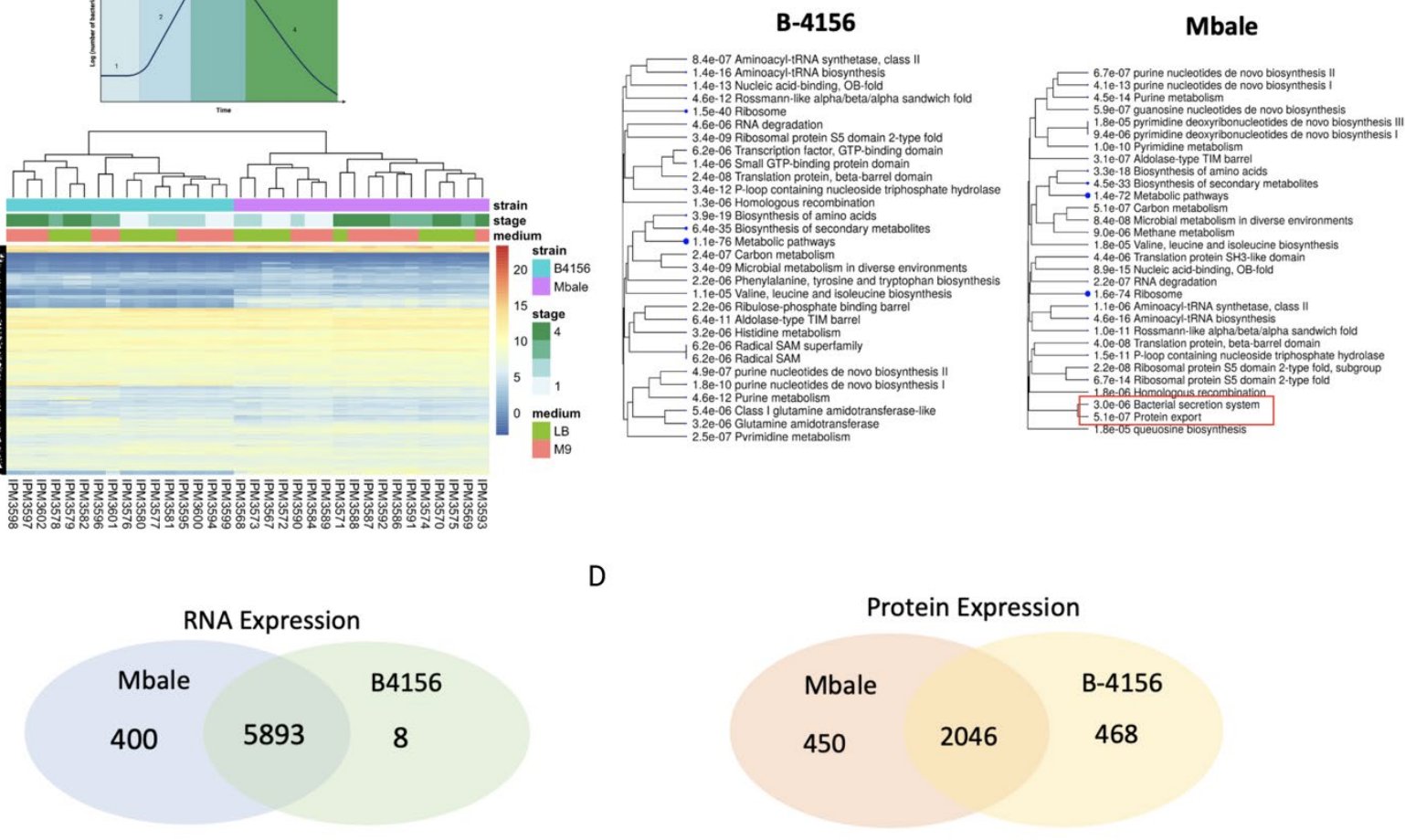

Figure 3: RNA and protein expression of the B-4156 and Mbale strains. A) Culture growth stages (top) and unsupervised hierarchical clustering (bottom) of the RNA transcript levels of the most variable genes expressed in the Mbale and type strains of $P$. thiaminolyticus. Clusters separate primarily according to strains and secondarily on the basis of stage of growth and media. B) Gene ontology of the 450 proteins uniquely identified in proteomic data for the B4156 strain (left) and the 468 proteins unique to the Mbale strain (right). P-values indicate the extent of enrichment of the genes of each indicated ontological group in the set of genes unique to each of the strains. Bacterial secretion system and protein export genes related to the SecA pathway uniquely represented in the Mbale strain are highlighted in red. C,D) Comparison of RNA (C) and protein (D) expression between the Mbale and B-4156 strains. 


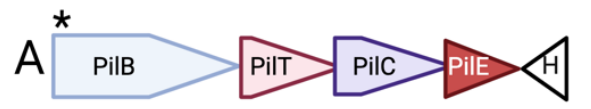

Mbale

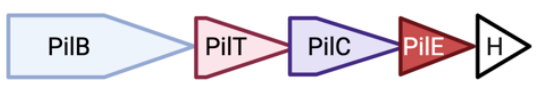

Mbale2 and Mbale3
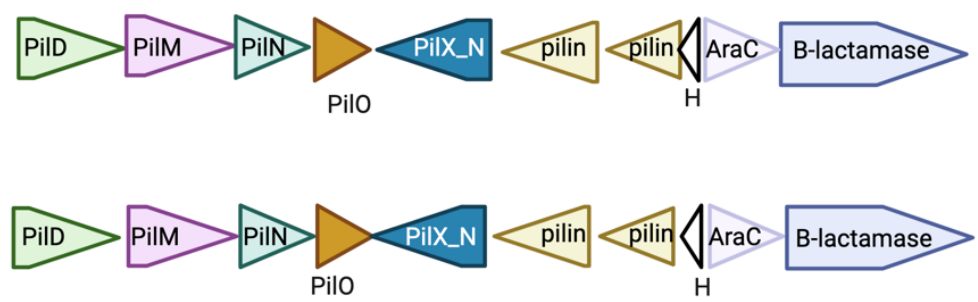

PilO

B

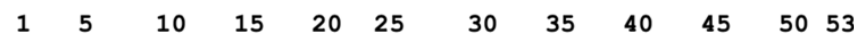

RLGxxLLxxGLIXxxxLxxxLxxQxxxxxRLGxxLLxxGLIxxxxLxxxLxxQ

PilB_Mbale 1 ---MKQRKRIGELMVEVGLITPAQLQHALAVQAKRKGRLGDVLLSEGLITEEQLIEVLDYQLGIPHVQLYRHHIEQEI I 76

FLT $4 \overline{3} 109201--$ MKQRKRIGELMVEVGLITPAQLQHALAVQAKRKGRLGDVLLSEGLITEEQLIEVLDCACGAGNAEAVL-------- 68

PilB1_Cdiff 1 ---MAKKVRIGDKLVEKGYITEEQLKWALSEQKNSGKRLGEFLVQEGLIDSNLIISVLKELLDIESIFLEGTEIDTLAT 74

PilB2_Cperf 1 -MISYQKKRLGDILIESGKLTEDRLKEALLIQKQVGKRLGEILVEQNFVTEEDIIEVLEKQLNIERVNLEIITIDRRAI 78

PilB Paerug 2 TMSNQQHSRLGQILINKGLISAAQLDAALQAQLSNHKRLGETLIEQGLLSERQLKKALKKQTNLRLAATLVAALLSPFQ 80

PILB MYXXD 1 ----MSGRLGELLVRENLISVQQLRKAQEEQQKNGTRIGTALVKTGAIEESKLTDFLSKQYGVPAINLKDFDVEPDII 74

NFRB ECOLI 481 TGDTRSLRPLGQILLENQVITEEQLDTALRNRVE-GLRLGGSMLMQGLISAEQLAQALAEQNGVAWESIDAWQIPSSLI 558

5HTL VCMShE 1 MPINKLRKRLGDLLVEEGIVSEAQLEQALNAQKNTGRRLGDTLISLGFLSETQLLNFLAQQLSLPVIDLSRAHVDIDAV 79

$\overline{5 H T L / S E C}$ STR

MPINLRKLLDLLVEEGIVSEAQLEQALNAQKNTGRLLGDTLISLGFLSETQLLNFLAQQLSLPVIDLSRAHVDIDAV
-

C

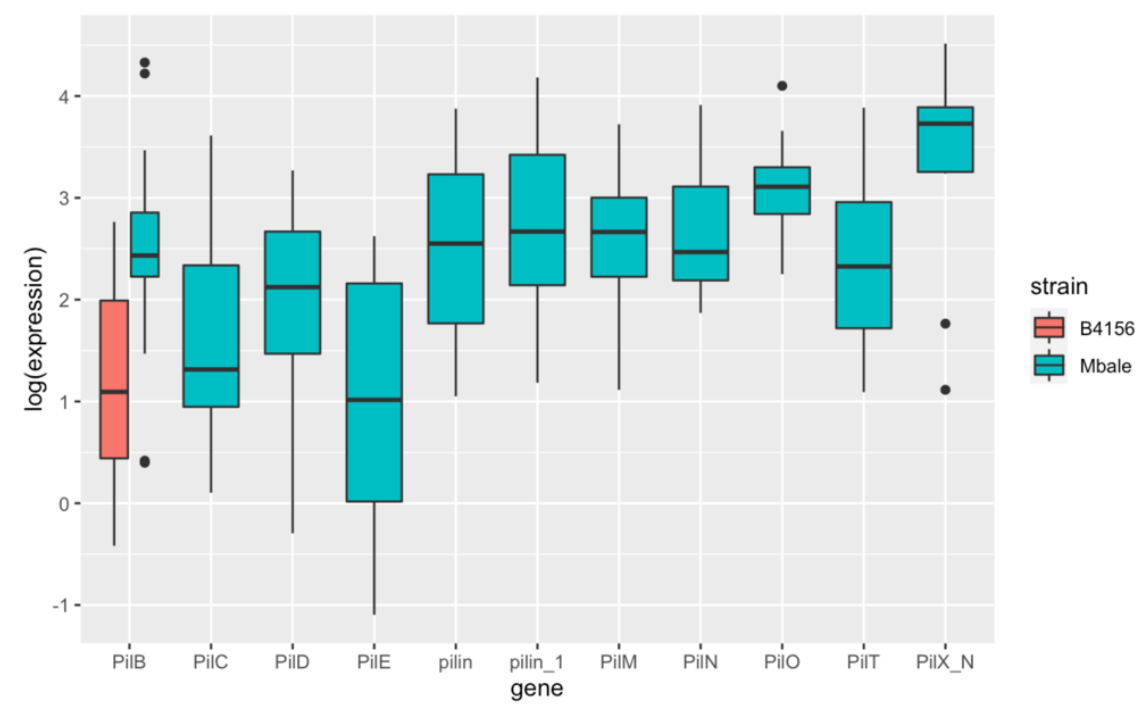

Figure 4: Predicted insertion carries the full Gram-positive T4P operon. A) The T4P operon

present in all three clinical isolates and absent in the B-4156 strain located in the predicted

mobile genetic element insertion (in strain Mbale, locus tags FLT15_06255 - FLT15_06190).

The genes were annotated with RAST or PGAP and/or with hits to the COG and Pfam databases.

PilFind [33] was used to identify potential pilins (light brown). White triangles designate

hypothetical proteins of unknown function. * indicates a c-di-GMP-binding site in PilB. B) 
Sequence alignment of the N-terminal fragment of PilB from strain Mbale (GenBank accession NGP58005.1) and truncated protein FLT43_10920 (GenBank: QDM43956.1) from $P$. thiaminolyticus type strain B-4156 against experimentally characterized MshEN domains. The top line shows the conserved c-di-GMP-binding site of the MshEN domain, which consists of tandem 24-aa motifs separated by a 5-aa insert [54]. Aligned sequences include MshEN domains of PilB proteins from Clostridioides difficile [82], Clostridium pefringens [81] Pseudomonas aeruginosa (PA3740) [54, 88] and Myxococcus xanthus (MXAN_5788) [89], and from Escherichia coli NfrB [90, 91]. The bottom two lines show the sequence and secondary structure (H, $\alpha$-helix) of the structurally characterized MshEN protein from Vibrio cholerae (VC_0405, $[54,92])$. Conserved hydrophobic residues are shaded yellow, conserved Gly residues are shaded green. C) Expression levels of the pil genes obtained from the RNA-seq data. 
A

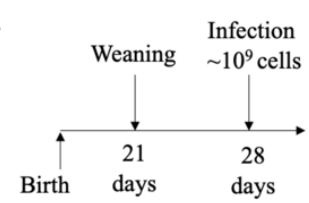

D

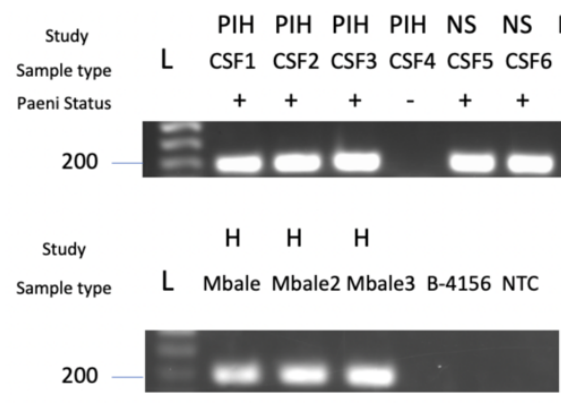

C

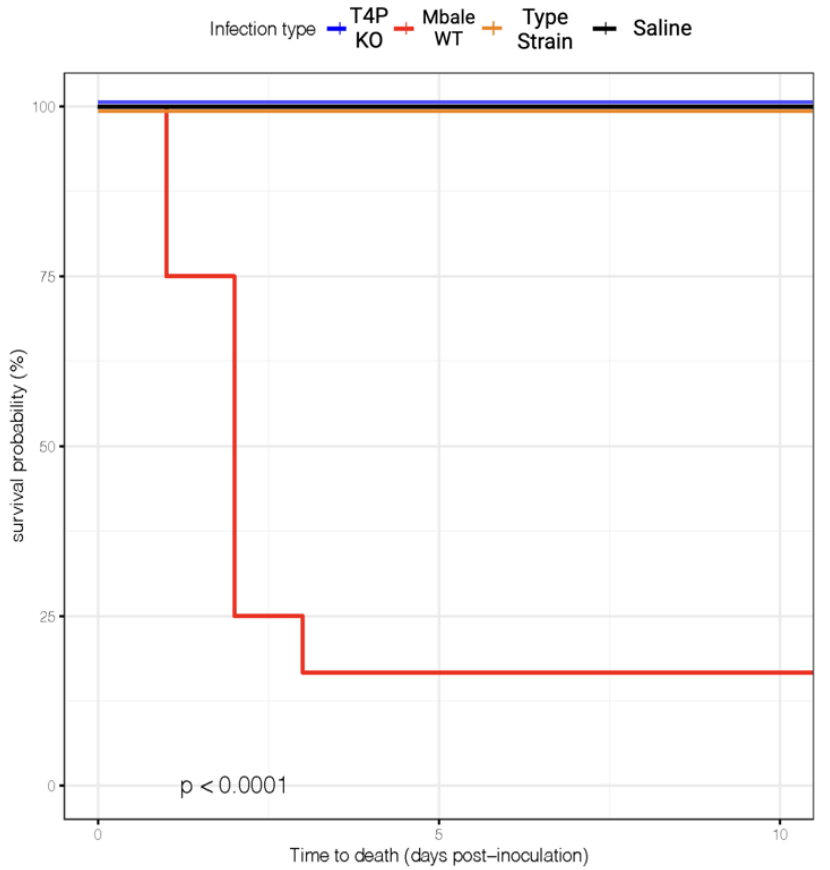

Figure 5: The T4P is a critical virulence factor in all three clinical isolates A) Mouse sepsis model of infection with injection planned post-weaning on day 28 of life. B) Cas9 containing vector under the control of the mannose promoter used for CRISPR-Cas9 knockout with the homology directed region (HDR), small guide RNA (sgRNA) and kanamycin resistance gene (kanR) for selection. C) Kaplan-Meier survival curve depicting survival of mice following injection of the T4P knockout strain $(n=9$, blue), the wildtype Mbale strain ( $\mathrm{n}=9$, red), the type strain B-4156 strain ( $\mathrm{n}=9$, orange) or vehicle control (black) $(\mathrm{p}<0.0001)$. D) Amplification of the pilT gene in cerebrospinal fluid (CSF) or bacterial culture $(\mathrm{H})$ from infants with postinfectious hydrocephalus (PIH) or neonatal sepsis (NS). Paenibacillus status (Paeni status) was determined by qPCR of the thiaminase gene previously defined and was $100 \%$ concordant. (Morton). L, DNA ladder. 
Table 1: Genomic Feature Summary of $P$. thiaminolyticus Strains. Assembly summary along with Genomic Features of the type strain, B-4156, and clinical strain, Mbale, designated by PARTIC and RefSeq

\begin{tabular}{|c|c|c|c|c|c|c|c|c|}
\hline Assembly Features & \multicolumn{2}{|c|}{ B-4156 } & \multicolumn{2}{|c|}{ Mbale } & \multicolumn{2}{|c|}{ Mbale2 } & \multicolumn{2}{|c|}{ Mbale3 } \\
\hline BioProject Accession & \multicolumn{2}{|c|}{ PRJNA552222 } & \multicolumn{2}{|c|}{$\underline{\text { PRJNA552221 }}$} & \multicolumn{2}{|c|}{ PRJNA799352 } & \multicolumn{2}{|c|}{ PRJNA799352 } \\
\hline Chromosomes & \multicolumn{2}{|l|}{1} & \multicolumn{2}{|l|}{1} & \multicolumn{2}{|l|}{1} & \multicolumn{2}{|l|}{1} \\
\hline $\begin{array}{l}\text { Uncharacterized } \\
\text { contigs }\end{array}$ & \multicolumn{2}{|l|}{0} & \multicolumn{2}{|l|}{1} & \multicolumn{2}{|l|}{0} & \multicolumn{2}{|l|}{0} \\
\hline $\begin{array}{l}\text { Pred. extra- } \\
\text { chromosomal phages }\end{array}$ & \multicolumn{2}{|l|}{0} & \multicolumn{2}{|l|}{2} & \multicolumn{2}{|l|}{0} & \multicolumn{2}{|l|}{1} \\
\hline Size (kbp) & \multicolumn{2}{|c|}{6,613} & \multicolumn{2}{|c|}{6,932} & \multicolumn{2}{|c|}{6,460} & \multicolumn{2}{|c|}{6,573} \\
\hline$\overline{\mathrm{GC} \%}$ & \multicolumn{2}{|c|}{53.6} & \multicolumn{2}{|c|}{53.3} & \multicolumn{2}{|c|}{53.7} & \multicolumn{2}{|c|}{53.5} \\
\hline Genomic Features & PATRIC* & RefSeq & PATRIC* & RefSeq & PATRIC* & RefSeq & PATRIC* & RefSeq \\
\hline$\overline{\mathrm{CDS}}$ & 6605 & 5710 & 7206 & 6258 & 6563 & & 7015 & \\
\hline Repeat region & 129 & 5 & 162 & 11 & 120 & & 116 & \\
\hline CRISPR repeat & 124 & 0 & 153 & 0 & 31 & & 107 & \\
\hline CRISPR spacer & 119 & 0 & 144 & 0 & 28 & & 99 & \\
\hline tRNA & 83 & 83 & 86 & 86 & 16 & & 83 & \\
\hline Regulatory & 83 & 30 & 31 & 31 & 0 & & 0 & \\
\hline misc RNA & 27 & 0 & 24 & 0 & 0 & & 0 & \\
\hline misc binding & - & - & 10 & 10 & 0 & & 0 & \\
\hline CRISPR array & 24 & 0 & 9 & 0 & 3 & & 8 & \\
\hline rRNA & 1 & 24 & 4 & 24 & 16 & & 15 & \\
\hline ncRNA & 0 & 3 & 0 & 3 & 0 & & 0 & \\
\hline tmRNA & 0 & 1 & 0 & 1 & 0 & & 0 & \\
\hline Protein Features & PATRIC & RefSeq & PATRIC & RefSeq & PATRIC & RefSeq & PATRIC & RefSeq \\
\hline $\begin{array}{l}\text { Hypothetical } \\
\text { Proteins (\%) }\end{array}$ & $2661(40)$ & 810 & 3171 & 1138 & 2750 & & 3002 & \\
\hline $\begin{array}{l}\text { Protein with } \\
\text { functional } \\
\text { assignment }(\%)\end{array}$ & $3944(60)$ & 4900 & 4035 & 5120 & 3813 & & 4013 & \\
\hline
\end{tabular}


Abbreviations: CRISPR, clustered regularly interspaced short palindromic repeats; pred.,

predicted; tRNA, transfer ribonucleic acid; rRNA, ribosomal ribonucleic acid; RNA, ribonucleic acid; misc, miscellaneous; kbp, kilobase pairs; GC \%, guanine-cytosine percent; Pred., Predicted* Annotation run by RASTtk 
bioRxiv preprint doi: https://doi.org/10.1101/2022.01.24.477451; this version posted January $24,2022$. The copyright holder for this preprint

(which was not certified by peer review) is the author/funder. This article is a US Government work. It is not subject to copyright under 17 USC 105 and is also made available for use under a CCO license.

Table 2: Predicted Protein by Subsystem from RASTtk Annotation

\begin{tabular}{|c|c|c|c|c|}
\hline Subsystems [Subsystem (genes)] & B-4156 & Mbale & Mbale2 & Mbale3 \\
\hline Metabolism & $91(745)$ & $93(767)$ & $92(742)$ & $94(768)$ \\
\hline Cofactors, Vitamins, Prosthetic Groups & $21(228)$ & $22(246)$ & $20(231)$ & $21(227)$ \\
\hline Amino Acids and Derivatives & $29(227)$ & $29(225)$ & $29(220)$ & $29(241)$ \\
\hline Fatty Acids, Lipids, and Isoprenoids & $11(88)$ & $11(91)$ & $11(88)$ & $11(92)$ \\
\hline Carbohydrates & $9(64)$ & $8(65)$ & $9(60)$ & $9(69)$ \\
\hline Nucleosides and nucleotides & $8(64)$ & $9(62)$ & $8(62)$ & $4(27)$ \\
\hline Iron acquisition and metabolism & $4(25)$ & $4(25)$ & $4(28)$ & $4(17)$ \\
\hline Phosphate metabolism & $1(20)$ & $2(21)$ & $2(12)$ & $2(15)$ \\
\hline Metabolite damage and mitigation & $4(17)$ & $4(17)$ & $4(25)$ & $2(7)$ \\
\hline Secondary metabolism & $2(7)$ & $2(10)$ & $2(10)$ & $2(5)$ \\
\hline Nitrogen Metabolism & $1(4)$ & $1(4)$ & $2(5)$ & $2(5)$ \\
\hline Sulfur Metabolism & $1(1)$ & $1(1)$ & $1(1)$ & $1(1)$ \\
\hline Protein Processing & $44(249)$ & $43(255)$ & $42(237)$ & $41(225)$ \\
\hline Protein Synthesis & $31(201)$ & $31(203)$ & $30(188)$ & $29(177)$ \\
\hline Protein Fate & $13(48)$ & $12(52)$ & $12(49)$ & $12(48)$ \\
\hline Energy & $28(205)$ & $29(218)$ & $27(209)$ & $29(235)$ \\
\hline Energy and Precursor Metabolites Generation & $18(124)$ & $20(141)$ & $18(134)$ & $20(159)$ \\
\hline Respiration & $10(81)$ & $9(77)$ & $9(75)$ & $9(76)$ \\
\hline Cellular Processes & $27(174)$ & $27(183)$ & $27(175)$ & $26(175)$ \\
\hline Cell Cycle, Cell Division and Death & $11(82)$ & $11(82)$ & $13(82)$ & $11(83)$ \\
\hline Prokaryotic cell differentiation & $13(77)$ & $13(83)$ & $11(78)$ & $12(77)$ \\
\hline Mobility and Chemotaxis & $1(9)$ & $1(9)$ & $1(9)$ & $1(9)$ \\
\hline Clustering-based subsystems & $1(5)$ & $1(8)$ & $1(5)$ & $1(5)$ \\
\hline Microbial communities & $1(1)$ & $1(1)$ & $1(1)$ & $1(1)$ \\
\hline Stress Response, Defense, Virulence & $36(120)$ & $17(119)$ & $32(121)$ & $31(124)$ \\
\hline Resistance to antibiotics and toxic compounds & $19(66)$ & $17(61)$ & $15(65)$ & $15(124)$ \\
\hline Stress response: Heat/Cold & $2(17)$ & $2(22)$ & $2(18)$ & $2(17)$ \\
\hline Stress response: Osmotic stress & $4(13)$ & $7(13)$ & $4(13)$ & $7(15)$ \\
\hline Stress response: Electrophile toxicity & $1(4)$ & $1(4)$ & $1(4)$ & $1(4)$ \\
\hline Host-pathogen interactions & $11(72)$ & $1(1)$ & $1(1)$ & $2(6)$ \\
\hline DNA Processing & $18(89)$ & 19 (117) & $18(90)$ & $19(116)$ \\
\hline DNA Repair & $12(59)$ & $13(96)$ & $12(60)$ & $13(84)$ \\
\hline DNA uptake, competence & $2(16)$ & $2(28)$ & $2(15)$ & $2(16)$ \\
\hline DNA recombination & $2(5)$ & $1(4)$ & $2(6)$ & $2(5)$ \\
\hline DNA replication & $1(4)$ & $1(2)$ & $1(4)$ & $1(5)$ \\
\hline Membrane transport & $11(72)$ & $11(68)$ & $7(63)$ & $7(68)$ \\
\hline
\end{tabular}


bioRxiv preprint doi: https://doi.org/10.1101/2022.01.24.477451; this version posted January 24, 2022. The copyright holder for this preprint (which was not certified by peer review) is the author/funder. This article is a US Government work. It is not subject to copyright under 17 USC 105 and is also made available for use under a CCO license.

\begin{tabular}{|l|c|c|c|c|}
\hline ABC Transporters & $1(42)$ & $1(41)$ & $1(42)$ & $1(41)$ \\
\hline Cation transporters & $4(22)$ & $3(17)$ & $3(17)$ & $3(21)$ \\
\hline Multidrug efflux systems & $2(3)$ & $2(3)$ & $2(3)$ & $2(4)$ \\
\hline Protein secretion systems, Type VII & $3(4)$ & $0(0)$ & $0(0)$ & $0(0)$ \\
\hline Protein secretion systems, Type II & $1(1)$ & $1(2)$ & $1(1)$ & $1(2)$ \\
\hline Uni, Sym, Anti transporter & $0(0)$ & $1(1)$ & $0(0)$ & $0(0)$ \\
\hline RNA Processing & $12(52)$ & $12(54)$ & $12(51)$ & $2(16)$ \\
\hline Cell Envelope & $3(15)$ & $3(15)$ & $3(14)$ & $1(6)$ \\
\hline Regulation and cell signaling & $3(12)$ & $3(12)$ & $3(14)$ & $3(14)$ \\
\hline
\end{tabular}


Table 3: Predicted functional proteins in the clinical isolates but absent in the type strain B-4156

\begin{tabular}{|l|l|}
\hline Category & Predicted Function \\
\hline $\begin{array}{l}\text { Secondary } \\
\text { Metabolism }\end{array}$ & Phosphoribosylanthranilate isomerase (EC 5.3.1.24) \\
\hline $\begin{array}{l}\text { Phosphorus } \\
\text { Metabolism }\end{array}$ & Phosphoenolpyruvate phosphomutase (EC 5.4.2.9) \\
\cline { 2 - 2 } & Phosphoenopyruvate decarboxylase (EC 4.1.1.82) \\
\cline { 2 - 2 } $\begin{array}{l}\text { Membrane Transport } \\
\text { \& Secretion Systems }\end{array}$ & 2-aminoethylphosphonate: pyruvate aminotransferase (EC 2.6.1.37) \\
\cline { 2 - 2 } & Leader peptidase (Prepilin peptidase) (EC 3.4.23.43) \\
\cline { 2 - 2 } & Twitching motility protein PilT \\
\hline Cell Wall \& Capsule & Teichoic acid translocation permease protein TagG* \\
\hline
\end{tabular}

*Confirmed with RNASeq and Proteomics 
Table 4: Type IV pili predicted proteins in Paenibacillus thiaminolyticus Mbale

\begin{tabular}{|c|c|c|c|c|c|c|c|}
\hline \multirow{3}{*}{$\begin{array}{l}\text { Protein } \\
\text { function }\end{array}$} & \multirow{3}{*}{$\begin{array}{l}\text { Protein } \\
\text { domain } \\
\text { (COG, } \\
\text { Pfam) }\end{array}$} & \multicolumn{2}{|c|}{ Type II secretion } & \multicolumn{4}{|l|}{ Type IV pili } \\
\hline & & \multirow{2}{*}{$\begin{array}{l}\text { Escherichia } \\
\text { coli } \mathrm{K} 12\end{array}$} & \multirow{2}{*}{$\begin{array}{l}\text { Klebsiella } \\
\text { oxytoxa }\end{array}$} & \multirow{2}{*}{$\begin{array}{l}\text { Pseudomona } \\
\text { s aeruginosa }\end{array}$} & \multirow{2}{*}{$\begin{array}{l}\text { Clostridium } \\
\text { perfringens }\end{array}$} & \multicolumn{2}{|c|}{ Paenibacillus thiaminolyticus } \\
\hline & & & & & & Mbale1 & B-4156 \\
\hline $\begin{array}{l}\text { Pilus assembly } \\
\text { ATPase }\end{array}$ & $\begin{array}{l}\text { COG2804, } \\
\text { PF00437 }\end{array}$ & GspE & PulE & $\begin{array}{l}\text { PilB, } \\
\text { PA4526 }\end{array}$ & $\begin{array}{l}\text { PilB, } \\
\text { CPE1844, } \\
\text { CPE2286 }\end{array}$ & $\begin{array}{l}\text { FLT15_06255, } \\
\text { NGP58005.1, } \\
566 \text { aa }\end{array}$ & $\begin{array}{l}\text { FLT43 10920, } \\
\text { QDM43956.1, } \\
68 \text { aa }\end{array}$ \\
\hline $\begin{array}{l}\text { Pilus retraction } \\
\text { ATPase }\end{array}$ & $\begin{array}{l}\text { COG2805, } \\
\text { PF00437 }\end{array}$ & N/A & N/A & $\begin{array}{l}\text { PilT/PilU, } \\
\text { PA0395, } \\
\text { PA0396 }\end{array}$ & $\begin{array}{l}\text { PilT, } \\
\text { CPE1767 }\end{array}$ & $\begin{array}{l}\text { FLT15_06250, } \\
\text { NGP58004.1, } \\
362 \text { aa }\end{array}$ & N/A \\
\hline $\begin{array}{l}\text { Core membrane } \\
\text { protein }\end{array}$ & $\begin{array}{l}\text { COG1459, } \\
\text { PF00482 }\end{array}$ & GspF & PulF & $\begin{array}{l}\text { PilC, } \\
\text { PA4527 }\end{array}$ & $\begin{array}{l}\text { PilC, } \\
\text { CPE2285, } \\
\text { CPE1843 }\end{array}$ & $\begin{array}{l}\text { FLT15_06245, } \\
\text { NGP58003.1, } \\
403 \text { aа }\end{array}$ & $\mathrm{N} / \mathrm{A}$ \\
\hline $\begin{array}{l}\text { Prepilin/ } \\
\quad \text { pseudopilin }\end{array}$ & $\begin{array}{l}\text { COG2165, } \\
\text { PF07963, } \\
\text { COG4968 }\end{array}$ & $\begin{array}{l}\text { GspG, } \\
\text { GspH, GspI, } \\
\text { GspJ, GspK }\end{array}$ & PulG & $\begin{array}{l}\text { PilE/PilV/Pil } \\
\text { W PA4551, } \\
\text { PA4552/56 }\end{array}$ & $\begin{array}{l}\text { PilE, } \\
\text { CPE2284 }\end{array}$ & $\begin{array}{l}\text { FLT15_06240, } \\
\text { NGP58002.1, } \\
142 \text { aа }\end{array}$ & $\mathrm{N} / \mathrm{A}$ \\
\hline $\begin{array}{l}\text { Prepilin } \\
\text { peptidase }\end{array}$ & COG1989 & GspO & $\mathrm{PulO}$ & $\begin{array}{l}\text { PilD, } \\
\text { PA4528 }\end{array}$ & $\begin{array}{l}\text { PilD, } \\
\text { CPE2287 }\end{array}$ & $\begin{array}{l}\text { FLT15_06230, } \\
\text { NGP58000.1, } \\
255 \text { aа }\end{array}$ & N/A \\
\hline $\begin{array}{l}\text { Inner membrane } \\
\text { accessory } \\
\text { protein }\end{array}$ & COG4972 & GspL & PulL & $\begin{array}{l}\text { PilM, } \\
\text { PA5044 }\end{array}$ & $\begin{array}{l}\text { PilM, } \\
\text { CPE2283 }\end{array}$ & $\begin{array}{l}\text { FLT15_06225, } \\
\text { NGP57999.1, } \\
387 \text { aa }\end{array}$ & $\mathrm{N} / \mathrm{A}$ \\
\hline $\begin{array}{l}\text { Inner membrane } \\
\text { accessory } \\
\text { protein }\end{array}$ & PF05137 & GspM & PulM & $\begin{array}{l}\text { PilN, } \\
\text { PA5045 }\end{array}$ & $\begin{array}{l}\text { PilN, } \\
\text { CPE2282 }\end{array}$ & $\begin{array}{l}\text { FLT15_06220 } \\
\text { NGP57998.1, } \\
200 \text { aa }\end{array}$ & $\mathrm{N} / \mathrm{A}$ \\
\hline $\begin{array}{l}\text { Inner membrane } \\
\text { accessory } \\
\text { protein }\end{array}$ & $\begin{array}{l}\text { COG3167, } \\
\text { PF04350 }\end{array}$ & $\mathrm{N} / \mathrm{A}$ & N/A & $\begin{array}{l}\text { PilO, } \\
\text { PA5046 }\end{array}$ & $\begin{array}{l}\text { PilO, } \\
\text { CPE2281, } \\
\text { CPE2288 }\end{array}$ & $\begin{array}{l}\text { FLT15_06215 } \\
\text { NGP57997.1, } \\
252 \text { aa }\end{array}$ & $\mathrm{N} / \mathrm{A}$ \\
\hline $\begin{array}{l}\text { Major pilin/ } \\
\text { pseudopilin }\end{array}$ & $\begin{array}{l}\text { CPOG4969, } \\
\text { PF00114 }\end{array}$ & GspG & PulG & $\begin{array}{l}\text { PilA, } \\
\text { PA4525 }\end{array}$ & $\begin{array}{l}\text { PilA, } \\
\text { CPE2288 }\end{array}$ & $\mathrm{N} / \mathrm{A}$ & $\mathrm{N} / \mathrm{A}$ \\
\hline $\begin{array}{l}\text { Outer membrane } \\
\text { secretin }\end{array}$ & $\begin{array}{l}\text { COG1450, } \\
\text { PF00263 }\end{array}$ & GspD & PulD & $\begin{array}{l}\text { PilQ, } \\
\text { PA5048 }\end{array}$ & $\mathrm{N} / \mathrm{A}$ & $\mathrm{N} / \mathrm{A}$ & $\mathrm{N} / \mathrm{A}$ \\
\hline $\begin{array}{l}\text { Pilus Assembly } \\
\text { protein }\end{array}$ & $\begin{array}{l}\text { COG4726, } \\
\text { PF14341 }\end{array}$ & $\mathrm{N} / \mathrm{A}$ & $\mathrm{N} / \mathrm{A}$ & $\begin{array}{l}\text { PilX, } \\
\text { PA4553 }\end{array}$ & PilX_N & $\begin{array}{l}\text { FLT15_06210, } \\
\text { NGP57996.1, } \\
475 \text { aа }\end{array}$ & $\mathrm{N} / \mathrm{A}$ \\
\hline
\end{tabular}

